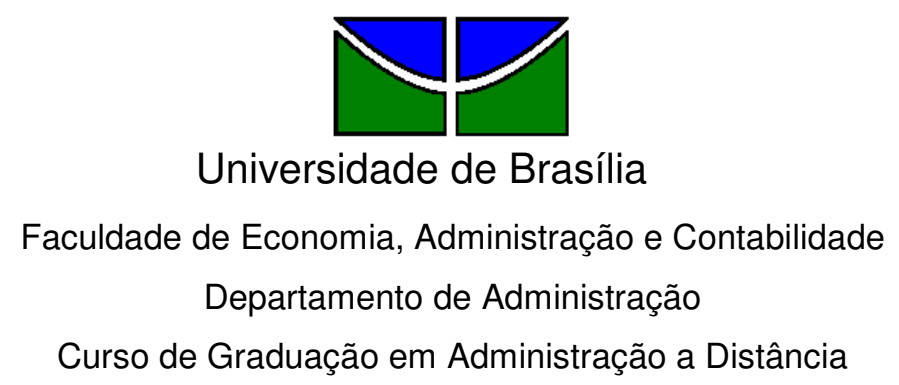

KATIA FRANCISCO DE LIMA

\title{
NÍVEL DE CONTROLE SOCIAL NA REDE DE EQUIPAMENTOS PÚBLICOS DE ALIMENTAÇÃO E NUTRIÇÃO
}

Brasília - DF 


\section{KATIA FRANCISCO DE LIMA}

\section{NÍVEL DE CONTROLE SOCIAL NA REDE DE EQUIPAMENTOS PÚBLICOS DE ALIMENTAÇÃO E NUTRIÇÃO}

Monografia apresentada a Universidade de Brasília (UnB) como requisito parcial para obtenção do grau de Bacharel em Administração.

Tutor-Orientador: Prof. Espec. Josias Rodrigues Alves

Supervisor do Eixo: Prof. Dr. José Matias-Pereira

Brasília - DF 
Lima, Katia Francisco de

Nível de Controle Social na Rede de Equipamentos Públicos de

Alimentação de Nutrição / Katia Francisco de Lima. - Brasília, 2010.

$50 \mathrm{f}$. : il.

Monografia (bacharelado) - Universidade de Brasília, Departamento de Administração - EaD, 2010.

Tutor-Orientador: Prof. Espec. Josias R. Alves, Supervisor do Eixo: Prof. Dr. José Matias-Pereira, Departamento de Administração.

1. Controle Social 2. Accountability 3. Segurança Alimentar. 4. Equipamentos Públicos de Alimentação e Nutrição. I. Título. 


\title{
KATIA FRANCISCO DE LIMA
}

\section{NÍVEL DE CONTROLE SOCIAL NA REDE DE EQUIPAMENTOS PÚBLICOS DE ALIMENTAÇÃO E NUTRIÇÃO}

\begin{abstract}
A Comissão Examinadora, abaixo identificada, aprova o Trabalho de Conclusão do Curso de Administração da Universidade de Brasília da aluna Katia Francisco de Lima
\end{abstract}

\section{Katia Francisco de Lima}

Prof. Espec. Josias Rodrigues Alves

Professor-Orientador

Prof. Dr. José Matias-Pereira Professor-Supervisor
Prof. Msc. Tiago Conde Teixeira

Professor-Avaliador

Brasília, 04 de dezembro de 2010 


\section{AGRADECIMENTOS}

A Universidade de Brasília, na pessoa do Prof. Dr. José Matias-Pereira pelo desafio de integrar a Universidade Aberta do Brasil.

Aos gestores da Rede de Equipamentos Públicos de Alimentação de Nutrição que prontamente atenderam aos meus pedidos.

Aos colegas Juliane Helriguel, Ísis Leite e Bruno Jansen pelo apoio com ideias e ideais. A Juliane Helriguel meu carinho e minha admiração profissional.

Ao meu marido Lindomar Oliveira pela presença e apoio, obrigada. 
"Meu papel no mundo não é só de constatar o que ocorre, mas também o de quem intervém como sujeito de ocorrências. Não sou apenas objeto da história, mas seu sujeito igualmente. No mundo da história, da cultura, da política, constato não para me adaptar, mas para mudar." (Paulo Freire). 


\section{RESUMO}

A premissa deste trabalho é avaliar o nível de controle social na rede de equipamentos públicos de alimentação e nutrição, trazendo à discussão aspectos de accountabilty societal agrupados aos conceitos de políticas públicas, políticas sociais, desenvolvimento da política nacional de segurança alimentar e nutricional, controle na administração pública e controle social. A pesquisa foi desenvolvida com a aplicação de questionário semi-estruturado coletando dados primários junto a 290 unidades da rede de equipamentos públicos de alimentação e nutrição utilizando o método de estudo quantitativo com caráter transversal. Os resultados foram analisados por meio estatística descritiva para interpretação dos dados coletados e não foram realizados testes de validade estatística em virtude das características da pesquisa e do tamanho da amostra. Os 78 questionários respondidos $(27,2 \%$ do universo de pesquisa) foram analisados individualmente (análise univariada) sendo também explorada a relação entre as variáveis estudadas (análise multivariada). Os resultados encontrados demonstram que há participação social na rede de equipamentos públicos de alimentação e nutrição com a presença de grupos gestores $(42,3 \%)$, associação de moradores $(35,9 \%)$, consultas públicas $(19,2 \%)$ e conselhos comunitários (15,4\%), além de conselhos institucionais em $83 \%$ do universo pesquisado. Tais dados corroboram os argumentos em prol da ampliação da participação social, tanto no processo de decisão sobre as políticas, quanto no direcionamento das ações realizadas nos equipamentos públicos de alimentação e nutrição. Além disso, a presença de outros mecanismos de participação social deve ser valorizada e estimulada na busca de acúmulo de capital social. Alguns aspectos do accountability, como o acesso as informações públicas dos equipamentos precisam ser melhorados, pois há constante uso de meios de divulgação como o mural informativo $(42,3 \%)$ e até mesmo a não divulgação dos dados $(16,6 \%)$ configurando como práticas que podem limitar o acesso aos dados. Evidencia-se que deve ser aprimorada a participação dos conselhos institucionais e assim, consequentemente, buscar-se a melhoria dos mecanismos de accountability na gestão do equipamento público, sempre com destaque para os conselhos de segurança alimentar e nutricional.

Palavras-chave: Controle Social. Accountability. Conselhos de Políticas Sociais. 


\begin{abstract}
This paper premise is to assess social control level in public equipment network of food and nutrition, bringing to discussing aspects of society accountability grouped by concepts of public policy, social policy, food and nutritional security policy development, control in public administration and social control. The survey was developed with the application of questionnaire semi-structured gathering primary data along 290 food and nutrition public equipment units using cross-sectional quantitative study. The results were analyzed using descriptive statistics on the data collected and statistical validity tests have not been conducted based on research characteristics and sample size. The 78 questionnaires (27.2\% of search universe) were examined individually (univariate) being also explored the relationship between the variables studied (multivariate analysis). Results show that there is social participation in food and nutrition public equipment network with the presence of class representative (42.3\%), residents associations (35.9\%), public consultations $(19.2 \%)$ and community councils (15.4\%), making institutional councils in $83 \%$ of the universe searched. Such data corroborate with the arguments favorable to extension of social participation, both at decision-making on policies and the targeting of actions performed on food and nutrition public facilities. Moreover, the presence of other mechanisms of social participation should be valued and stimulated in efforts for social capital stock. Some aspects of accountability, such as access to public information equipment need to be improved, because there is constant media use such as informative panels (42.3\%) and data closure (16.6\%) proving to be practices that can limit access to data. Shows up that institutional councils participation must be enhanced and also the need for accountability improvement in public equipment management, focusing on the food and nutritional security councils.
\end{abstract}

Palavras-chave: Social Control. Accountability. Social Policy Council. 


\section{LISTA DE SIGLAS}

CAISAN - Câmara Intersetorial de Segurança Alimentar CGEP - Coordenação-Geral de Equipamentos Públicos CNAS - Conselho Nacional de Assistência Social CONSEA - Conselho Nacional de Segurança Alimentar e Nutricional DESAN - Departamento de Sistemas Descentralizados de Segurança Alimentar e Nutricional

DHAA - Direito Humano à Alimentação Adequada

EPAN - Equipamentos Públicos de Alimentação e Nutrição

MDS - Ministério do Desenvolvimento Social e Combate à Fome

PNSAN - Política Nacional de Segurança Alimentar e Nutricional

REDESAN - Rede de Equipamentos Públicos de Alimentação e Nutrição

SAN - Segurança Alimentar e Nutricional

SESAN - Secretaria Nacional de Segurança Alimentar 


\section{SUMÁRIO}

1 INTRODUÇÃO

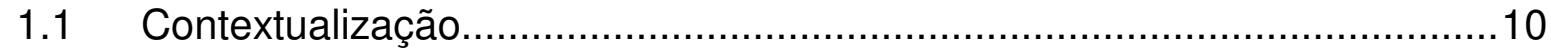

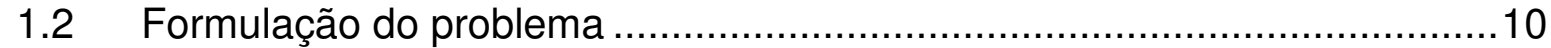

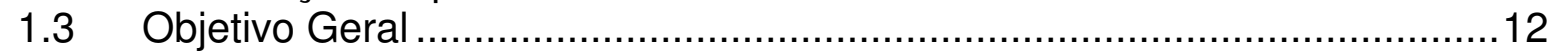

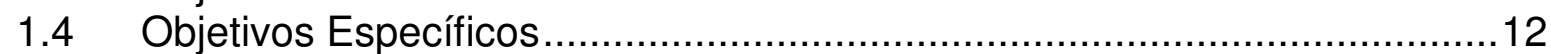

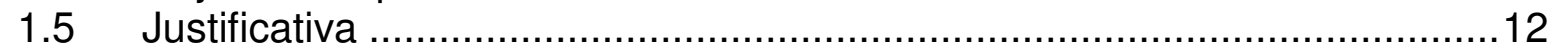

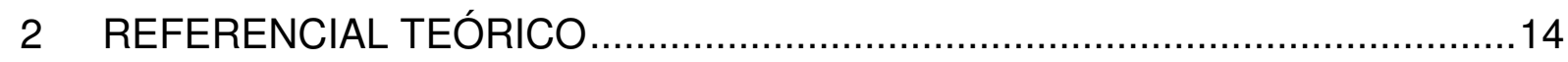

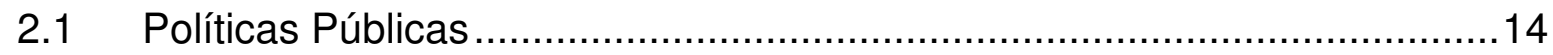

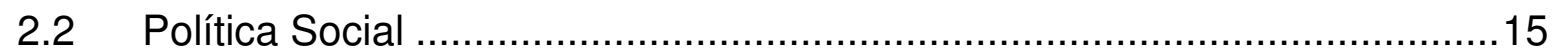

2.3 Política Nacional de Segurança Alimentar e Nutricional ...........................16

2.4 Controle na Administração Pública .......................................................20

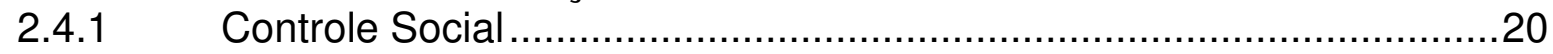

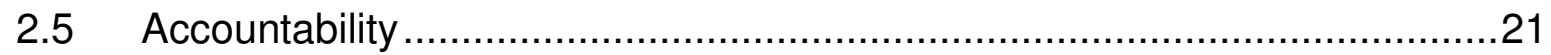

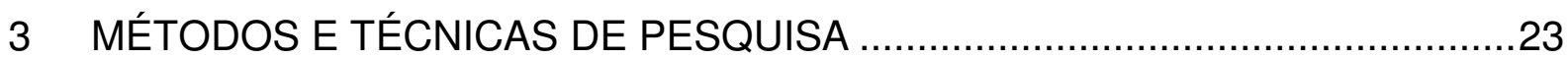

3.1 Caracterização da organização, setor ou área ……………...................24

3.2 População e amostra ou participantes do estudo ...................................24

3.3 Caracterização dos instrumentos de pesquisa ......................................24

3.4 Procedimentos de coleta e de análise de dados.....................................25

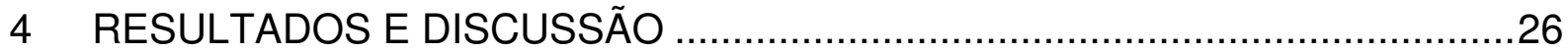

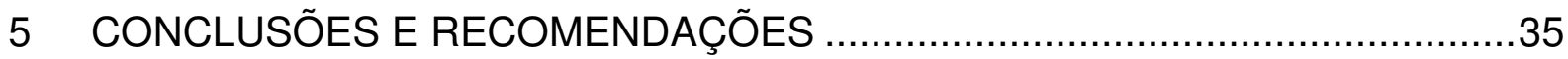

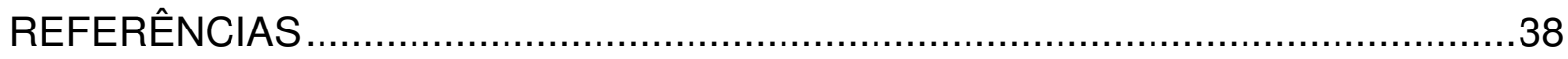

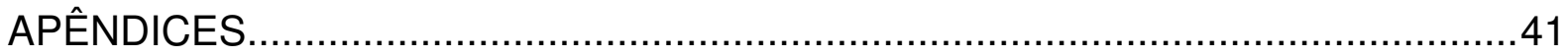

Apêndice A - Questionário .......................................................................... 42

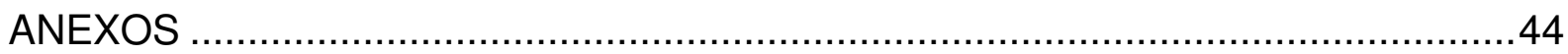

Anexo B - Tipologia das Cozinhas Comunitárias da REDESAN ............................50 


\title{
1 INTRODUÇÃO
}

Os conselhos sociais tornaram-se um importante ator no exercício do controle social das políticas públicas que conduzem o desenvolvimento social brasileiro.

\begin{abstract}
O intelectual Gramsci posicionou a sociedade civil como parte do Estado, tendo como função a elaboração do consentimento à dominação política através de diversas instituições, como as escolas, os sindicatos, as igrejas, dentre outras, nas quais a classe dominante exerce hegemonia sobre outros segmentos sociais, a partir da qual ocorrem as disputas por controle político. (VIEIRA, 2005, p. 607).
\end{abstract}

Sabe-se que os conselhos instituem-se em uma possibilidade de avanço da gestão de políticas públicas, pois permitem que práticas mais participativas sejam estimuladas, gerando responsabilidade pública, ou mesmo articulando mecanismos de accountability. Os conselhos são instâncias participativas que fomentam a prática de uma democracia direta e podem ser considerados um novo modelo de relação entre Estado e Sociedade. Melhor dizendo, a representatividade dos conselhos vai além, pois a constituição de 1988 permitiu uma nova chance a conformação destas instituições, incluem-se a partir daí os conselhos como parte do Estado (CARNEIRO, 2006).

As conformações e funções assumidas pelos conselhos sociais no Brasil tem sido vistas como confusas e complexas quando comparadas aos demais países. No Brasil, as instâncias de controle social se confundem e servem como mecanismos ou meras instituições de apoio à validação de políticas. Até onde vai a influência da sociedade civil, por exemplo, dentro de um conselho que tem sede e depende financeiramente de um espaço que lhe é cedido pelo poder público?

Considerando que os conselhos deveriam servir para aproximar o governo dos cidadãos e, desta forma, enfraquecer as redes de clientelismo, trazendo alianças e conflitos de interesses para esferas públicas de decisão; deveriam servir para permitir maior grau de acerto no processo de tomada de decisões; ajudar na identificação mais rápida de problemas e na construção de alternativas de ação; aumentar a transparência administrativa e pressionar as diversas áreas do governo em direção a ações mais integradas, é perceptível que as funções desempenhadas pelos Conselhos Sociais não tem sido satisfatórias e que o papel destes espaços devem ser mais debatido e esclarecido (CARNEIRO, 2006). 


\subsection{Contextualização}

No Brasil, a Segurança Alimentar e Nutricional - SAN é um direito humano que realiza-se por meio de políticas universais e é garantido na Constituição. No entanto, não é suficiente garantir a SAN se os processos que implementam as ações são pautados em relações clientelistas, baseando-se em troca de favores e até mesmo desrespeito aos valores culturais dos grupos atendidos. "A forma como os programas públicos são implementados é tão importante quanto a sua concepção, pois podem afetar tanto os aspectos objetivos quanto os subjetivos que determinam as capacidades humanas para viver e se alimentar de forma adequada". (IBASE, 2008, p. 14).

O objetivo da rede de equipamentos públicos de alimentação e nutrição REDESAN é garantir o direito à alimentação adequada e saudável à população em situação de insegurança alimentar e vulnerabilidade social. Sob este aspecto, as instâncias de controle social são atores importantes dessa política, pois atuam na seleção do público-alvo, na fiscalização do serviço prestado e no planejamento das ações sociais, buscando assim enfraquecer as redes de clientelismos e garantir a equidade e eficiência na prestação dos serviços.

\subsection{Formulação do problema}

O município tem participado de forma crescente das decisões sobre políticas públicas criando condições para que os conselhos municipais, ligados à gestão, envolvam-se neste processo decisório. A maioria dos conselhos tem atribuições relacionadas ao planejamento e fiscalização da aplicação dos recursos financeiros descentralizados da esfera federal ou estadual para a municipal (SPINELLI; COSTA, 2009).

Dessas atribuições, segundo citado por Côrtes (2004 apud SPINELLI; COSTA, 2009, p. 08) há um "grande potencial para interferir decisivamente nos rumos das políticas públicas. Isso porque esses canais participativos possuem, [...], potencial para exigir em nome da coletividade e do interesse público uma conduta responsável dos agentes públicos." 
A importância do trabalho que se apresenta está na busca de informações sobre uma realidade desconhecida que envolve a atuação dos conselhos institucionalizados e o nível de participação social na rede de equipamentos públicos de alimentação e nutrição. Alguns estudos, por exemplo, o realizado por Spinelli e Costa $(2009$, p. 40$)$ tem apontado que "há uma enorme distância entre o potencial que os conselhos locais de políticas públicas possuem e a atividade que essas instâncias tem, de fato, desempenhado." No caso da participação dos conselhos sociais na rede de equipamentos públicos de alimentação e nutrição há a exigência nos editais que regulam as seleções da aprovação, pelo conselho, da proposta de implantação do equipamento, isto é, se o projeto não for aprovado por uma instância de controle social ele não se habilitará na seleção.

Porém, para além dessa exigência inicial, não há informação sobre a atuação dessas instâncias em outras fases do programa e nem mesmo dos tipos de participação social que se apresentam como outras alternativas. Para isso desenvolveu-se como problema de pesquisa a pergunta "Qual o nível de participação e controle social, considerando os aspectos de accountability, presente na rede de equipamentos públicos de alimentação e nutrição?"

Estudo feito por Carneiro (2006, p. 163) aponta que "grande parte dos conselhos sociais executa tarefa que não constituem as atividades núcleo dos conselhos, que são o motivo de sua criação". Se este processo estiver ocorrendo com os conselhos criados para validar a política de segurança alimentar, é importante que se pense em ações com o objetivo de minimizar este problema e garantir os incentivos à participação mais consistente dessas instâncias sociais, reflexão que segue uma perspectiva trazida por Carneiro e Costa (2001 apud VIEIRA, 2005, p. 620) que afirma que não se pode "desconsiderar que os mecanismos de acompanhamento, por parte dos conselhos, da execução das políticas ainda são frágeis [...] dependente de condições sociais, políticas e institucionais ainda não totalmente exploradas e identificadas". 


\subsection{Objetivo Geral}

- Avaliar o nível de participação e controle social na rede de equipamentos públicos de alimentação e nutrição.

\subsection{Objetivos Específicos}

- Verificar a atuação das instâncias de controle social junto à rede de equipamentos públicos de alimentação e nutrição;

- Identificar mecanismos de integração com a comunidade atendida pela rede de equipamentos públicos de alimentação e nutrição;

- Identificar as formas de divulgação das informações públicas da rede de equipamentos públicos de alimentação e nutrição.

\subsection{Justificativa}

Para a instalação de qualquer um dos equipamentos públicos de alimentação e nutrição - EPAN que constituem a REDESAN é obrigatória à aprovação do projeto pelo Conselho Municipal ou Estadual de Segurança Alimentar Nutricional, pelo Conselho Municipal ou Estadual de Assistência Social ou na ausência destes, por outra instância de controle social instituída pelo poder público. Desta forma procurase valorizar e estabelecer a necessidade do controle social que passaria a ser exercido desde a formulação da proposta até o acompanhamento do funcionamento da unidade implantada.

Segundo o Instituto de Pesquisas Econômicas Aplicadas - IPEA, na publicação Comunicados da Presidência n 38 (BRASIL, 2010), nos últimos anos ocorreu um crescimento do papel do município na implementação das políticas sociais, sobretudo em termos de educação, saúde e assistência social. No ano de 2008, por exemplo, o conjunto dos municípios teve participação no gasto social brasileiro 53,8\% superior ao verificado em 1980 - isto é, antes da Constituição atual que amplia os poderes destes entes federativos - e participação social na 
conformação e gestão das políticas sociais brasileiras. Esta mesma publicação informa ainda que, de maneira geral, todas as principais políticas sociais possuem conselhos de participação social federal, estadual e municipal, quando não são acompanhadas por conferências populares que evidenciam a maior transparência e eficácia na aplicação dos recursos públicos.

A construção de um sistema de SAN passa, necessariamente, pelo fortalecimento das instâncias de controle social. Os equipamentos públicos de Alimentação e Nutrição, sendo parte deste sistema, se constituem em espaços para a atuação e fortalecimento dos conselhos. A partir do diagnóstico do nível de atuação, dos tipos e também do nível de envolvimento dos conselhos na condução e até mesmo na execução do planejamento, pode-se verificar o nível de atuação dessas instâncias, além de se identificar outros espaços de participação social que, apesar de não institucionais, tem grande importância. A análise desta situação auxiliará na avaliação do nível de controle social e, até mesmo, na proposta de ajustes para o processo participativo sob diversos aspectos. 


\section{REFERENCIAL TEÓRICO}

\subsection{Políticas Públicas}

Entende-se por política uma gama de ações e procedimentos que tem como objetivo a resolução pacífica de conflitos em torno da alocação de bens e recursos públicos. Os atores públicos, que são personagens envolvidos na execução das políticas, são figuras fundamentais no desenvolvimento dessas ações. Há uma importante distinção entre política pública e decisão política, sendo que a primeira requer mais que uma decisão, pretende ainda estratégias selecionadas para a implementação das decisões tomadas; já a segunda corresponde a uma escolha dentre um leque de alternativas, o que implica em hierarquia de preferências dos atores envolvidos. A decisão política em maior ou menor grau expressa a adequação entre os fins pretendidos e os meios disponíveis (MATIAS-PEREIRA, 2007).

A máquina estatal, estabelecida para planejar e executar suas próprias ações, entrou em crise de forma mais notória na década de 70 devido a fatores externos marcantes como a crise do petróleo e guerras, e a necessidade de respostas rápidas aos anseios da população mostraram que os sistemas estabelecidos eram inflexíveis e lentos. Esta estrutura, por sua conformação e administração, acabou sofrendo efeitos de deterioração de capacidade de resposta às necessidades e anseios da população e, consequentemente, queda da sua credibilidade. Por outro lado, havia uma crescente demanda de participação democrática nas decisões estatais, passando pela necessidade de implementar e de controlar os resultados gerados (SARAVIA, 2006).

Devido à necessidade de se posicionar de forma mais ágil junto à sociedade, nos anos 80 houve um fortalecimento progressivo de concepção da atividade governamental: a ação baseada no planejamento deslocou-se para a ideia de política pública; com a ajuda da tecnologia, descentralizar e permitir a participação social ficou mais fácil e as mudanças sociais tornaram-se factíveis e desejáveis (SARAVIA, 2006). Assim o processo de política pública, mostra-se como uma forma moderna de lidar com as incertezas decorrentes de mudanças do contexto em que 0 Estado está inserido. 
Saravia (2006, p. 28) afirma que "uma política pública é um fluxo de decisões públicas, orientado a manter o equilíbrio ou a introduzir desequilíbrios destinados a modificar essa realidade". O mesmo autor reconhece que o processo de política pública, por mais que já tenha sido sistematizado por alguns autores, não possui uma racionalidade manifesta, não sendo uma ordenação tranquila na qual cada ator sabe o seu papel.

A Constituição promulgada em outubro de 1988 é um marco para a cidadania brasileira. A Nova Carta proclamava o estabelecimento de um Estado democrático, reconhecedor de direitos civis, políticos, econômicos, sociais e culturais, e significava uma mudança na política pública que agora buscava o Estado do bemestar (BRASIL, 2009b).

\subsection{Política Social}

Wilensky (1975 apud BOBBIO; MATTEUCCI; PASQUINO, 2003) define o estado do bem-estar (Welfare State), ou assistencial como o estado que garante "tipos mínimos de renda, alimentação, saúde, habitação, educação, assegurados a todo o cidadão, não como caridade, mas como direito político." O referencial mundial para as ações de Estado de Bem Estar Social são os principais países do continente europeu, países que optaram por investir em política social e priorizaram recursos para esta área.

As demandas por políticas sociais foram trazidas pelos movimentos sociais, que tiveram importante papel nas conquistas conseguidas na Constituição de 1988, já que as anteriores sofriam forte crítica de caráter excludente. Estas conquistas aparecem neste documento desde o seu preâmbulo:

(...) instituir um Estado democrático, destinado a assegurar o exercício dos direitos sociais e individuais, a liberdade, a segurança, e bem-estar, o desenvolvimento, a igualdade e a justiça como valores supremos de uma sociedade fraterna, pluralista e sem preconceitos, fundada na harmonia social (...) (BRASIL, 1988).

A chegada da Constituição de 1988 também não veio desacompanhada da evolução do Estado na gestão das políticas assistenciais e sociais. As análises dos estudiosos apontam que as políticas assistenciais adotadas pelo Estado brasileiro, embora fossem consideras frágeis, assumiam importante relevância num período de 
baixos salários e de baixa cobertura do sistema contributivo, e que, embora por princípio seu atendimento devesse ser residual, o que ocorria era o atendimento por esses sistemas de parcelas significativas da população, assalariada ou não. Essa prática teve o efeito adverso de abrir espaço para o clientelismo das políticas sociais (CASTRO; RIBEIRO, 2009).

Apesar de meritocrático, o sistema adotado pelo regime militar funcionou bem na época do milagre brasileiro, com a adesão da massa assalariada que sustentava os serviços oferecidos pelo Estado; porém, na década de 70 houve uma reversão no crescimento do PIB, o que prejudicou a arrecadação com a diminuição dos empregos formais e, consequentemente, da base de sustentação das políticas sociais. A meritocracia se mostrou insuficiente para atender as necessidades de políticas sociais (CASTRO; RIBEIRO, 2009).

Castro e Ribeiro (2009, p.26), descrevem essa situação, que nos levou as mudanças consolidadas na Carta Política de 1988.

A configuração extremamente pró-cíclica da estrutura de financiamento das políticas sociais, que tinha se mostrado tão virtuosa no período de acelerado crescimento econômico, impõe um rápido estrangulamento ao sistema de políticas sociais então em vigor justamente quando as carências sociais ampliavam-se.

$\mathrm{Na}$ Constituição de 1988 destacam-se o estabelecimento de princípios que são fundamentais das políticas sociais como a descrição das bases da seguridade social, dos direitos ao acesso universal à saúde e a garantia de educação. Além dos avanços na relação entre os entes federados com a descentralização de ações de políticas sociais, considerou-se que as esferas locais, por estarem mais próximas aos cidadãos, seriam as mais adequadas para interpretar suas necessidades e implementar ações que as atendessem.

\subsection{Política Nacional de Segurança Alimentar e Nutricional}

Entendida como um aspecto da política social, as primeiras discussões sobre a temática da Segurança Alimentar e Nutricional remetem ao período que se seguiu à Primeira Guerra Mundial. No entanto, somente a partir da década de 1940 é que essas ações foram implementadas, o que ocorreu, principalmente, por meio das instituições de Previdência Social, mais especificamente por meio do Serviço de 
Alimentação da Previdência Social - SAPS. No Brasil, um ator importante na discussão deste processo é o geógrafo Josué de Castro que, em 1946, publicou a primeira edição do livro "Geografia da Fome", uma obra literária de essência social e progressista onde afirma que o fenômeno da fome deveria ser enfrentado por meio da implantação progressiva de políticas públicas e de políticas de salário mínimo. Entretanto, se esforços variados podem ser identificados desde então, foi apenas na década de 1990 que esta questão se destacou no âmbito do governo federal (JACOOUD; EL-MOR HADJAB; CHAIBUB, 2009).

Como marcos políticos tanto do Sistema quanto de uma Política de Segurança Alimentar e Nutricional citam-se dois eventos ocorridos em meados da década de 1980: a elaboração em 1985 do documento "Segurança Alimentar proposta de uma política de combate à fome" no âmbito no Ministério da Agricultura e a mobilização da sociedade civil, que levou à realização da I Conferência Nacional de Alimentação e Nutrição (CNAN), em 1986; em ambos se encontrava a proposta de constituir um Conselho Nacional de Segurança Alimentar e Nutricional (CONSEA) abarcando as múltiplas dimensões de SAN, e também propiciando a necessária participação da sociedade civil (BRASIL, 2009a).

Em 1992, o IPEA lança a publicação "Mapa da Fome" a qual denuncia que 32 milhões de brasileiros não têm renda para se alimentar. Como resposta a este cenário há a apresentação do "Plano Nacional de Segurança Alimentar" e estruturase a primeira experiência do CONSEA que teve a duração de dois anos, em 1993 e 1994, sendo interrompido em 1995 e retomado somente em 2003, ano em que o governo do Presidente Lula estabeleceu como objetivo prioritário o enfrentamento da fome e da miséria, materializado não apenas na criação do Ministério Extraordinário de Segurança Alimentar - MESA, por meio da Medida Provisória $n^{\circ} 103$, de $1^{\circ}$ de janeiro de 2003 e na reinstalação do CONSEA, por meio da Lei $n^{\circ} 10.683$ de 28 de maio de 2003, como também por meio do lançamento do programa Fome Zero, e, neste, um novo programa de transferência de renda: o Cartão Alimentação, que logo em seguida foi incorporada ao Cartão do Programa Bolsa Família (BRASIL, 2009a).

Com as ações de institucionalização, o tema da Segurança Alimentar e Nutricional emergiu, ora como parte da política de saúde, ora como ação assistencial, até afirmar-se em 2006, com a aprovação da Lei Orgânica de Segurança Alimentar e Nutricional (LOSAN), como política de proteção social. A LOSAN trouxe o fortalecimento do CONSEA, que recebeu as atribuições de propor 
diretrizes para política nacional da área, assim como de articular, acompanhar e monitorar a implementação e a convergência de ações inerentes a esta política. As ações do CONSEA são complementadas pelo Sistema Nacional de Segurança Alimentar - SISAN e visam executar e acompanhar os programas de segurança alimentar, por meio de ações realizadas em parceria com as três esferas de governo (União, Estados e Municípios) e a sociedade civil.

Como um dos desafios da política nacional de segurança alimentar e nutricional é a intersetorialidade, com este objetivo foi prevista na Lei Orgânica uma instância responsável por esta articulação que é a Câmara Interministerial de Segurança Alimentar e Nutricional - CAISAN, criada em 2007 mediante o Decreto $\mathrm{n}^{\circ}$ 6.273, envolve 19 ministérios com missão de promover a articulação e a integração dos órgãos e das entidades do governo federal ligados à temática (BRASIL, 2009a).

Os avanços no campo da Segurança Alimentar ganharam importante reforço em fevereiro de 2010, quando foi aprovada a Emenda Constitucional $n^{\circ} 64$ que inseriu no artigo 6 da Constituição Federal a alimentação como um dos direitos sociais e em 25 de agosto de 2010 com a assinatura do Decreto № 7.272 que assegura o direito humano à alimentação adequada e institui a Política Nacional de Segurança Alimentar e Nutricional - PNSAN.

Figura 1: Evolução da Segurança Alimentar e Nutricional no Brasil - Marcos Históricos

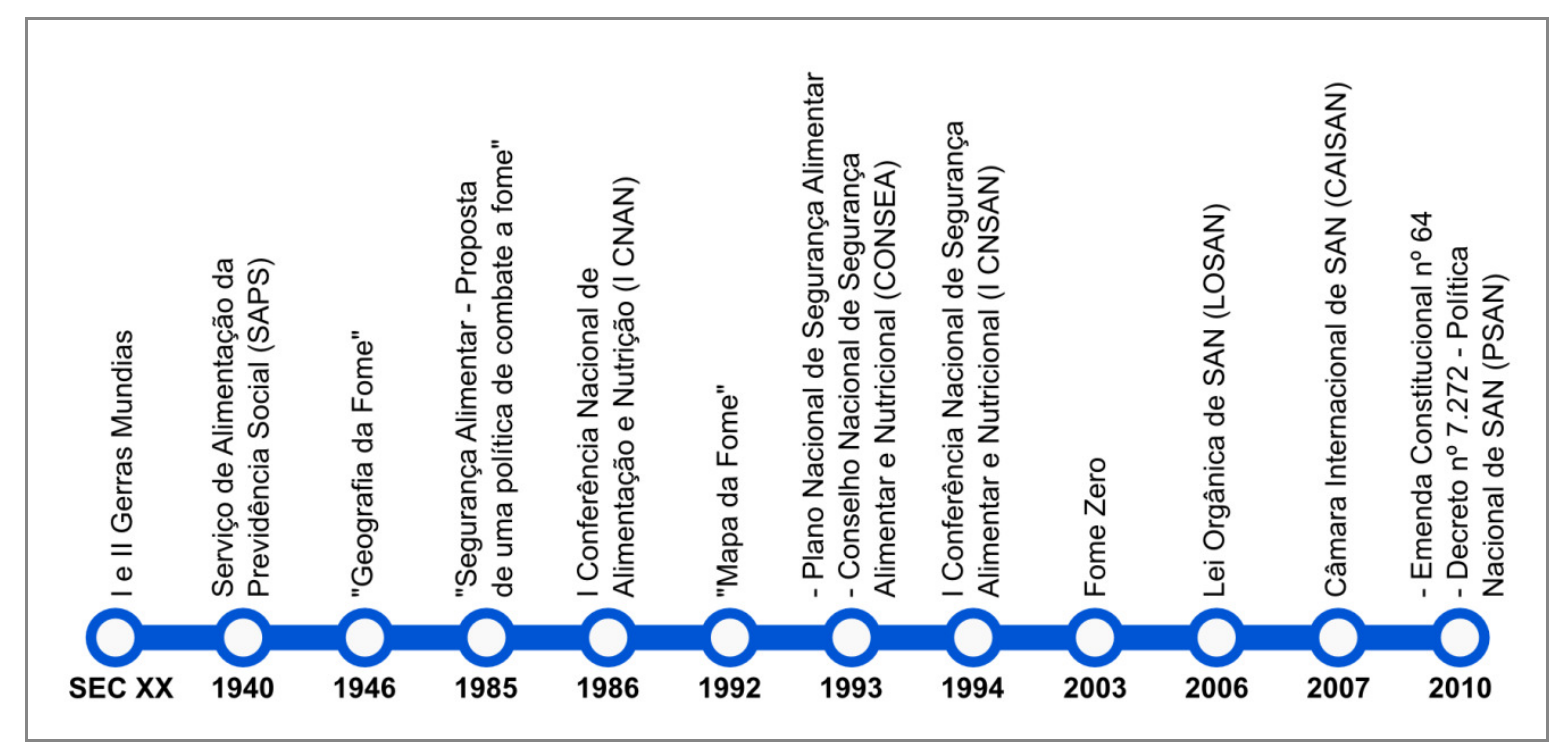

Atualmente, o principal responsável pelas políticas de segurança alimentar é o Ministério do Desenvolvimento Social e Combate à Fome - MDS. Este ministério 
foi criado de uma junção do extinto MAS (Ministério da Assistência Social), da Secretaria Gestora do Programa Bolsa Família e do MESA (Ministério Extraordinário de Segurança Alimentar) por meio do Decreto $n^{\circ} 5.074$, de 11 de maio de 2004, no âmbito deste Ministério, há a Secretaria Nacional de Segurança Alimentar - SESAN, que atualmente é responsável pela execução da política de segurança alimentar.

Como estratégia de atuação para o desenvolvimento da Política no âmbito estadual e municipal, a SESAN, por meio do Departamento de Sistemas Descentralizados de Segurança Alimentar e Nutricional - DESAN, tem como incumbência apoiar a estruturação de Rede de Equipamentos Públicos de Alimentação de Nutrição - REDESAN, com o objetivo de assegurar o direito à alimentação adequada das famílias em situação de insegurança alimentar, sendo ainda de responsabilidade deste departamento: planejar, coordenar, apoiar, e acompanhar a execução de ações e atividades que impactam no sistema agroalimentar regional, nas diferentes etapas do fluxo, seja de produção, circulação e distribuição ou ainda, preparo e consumo de alimentos.

Figura 2: Sistema Nacional de Segurança Alimentar e Nutricional (MDS, 2010). Fonte: SESAN.

\begin{tabular}{|c|c|c|c|}
\hline \multirow[t]{3}{*}{ Estratégia } & Produção & $\begin{array}{l}\text { Circulação } \\
\text { e Distribuição }\end{array}$ & Consumo \\
\hline & $\begin{array}{l}\text { Agricultura Urbana } \\
\text { e Periurbana }\end{array}$ & Bancos de Alimentos & Restaurantes Populares \\
\hline & Cisternas & $\begin{array}{l}\text { Feiras e Mercados } \\
\text { Populares }\end{array}$ & Cozinhas Comunitárias \\
\hline \multirow[t]{4}{*}{$\begin{array}{c}\text { Atuação do } \\
\text { MDS }\end{array}$} & Segunda Água & & $\begin{array}{l}\text { Distribuição } \\
\text { de Alimentos }\end{array}$ \\
\hline & $\begin{array}{l}\text { Produção Agroecológica } \\
\text { Integrada Sustentável }\end{array}$ & & \\
\hline & \multicolumn{3}{|c|}{ Programa de Aquisição de Alimentos } \\
\hline & \multicolumn{3}{|c|}{ Educação Alimentar } \\
\hline
\end{tabular}

A sistemática de funcionamento dos fluxos que envolvem a rede de produção e consumo de alimentos, tende a resultar na ampliação da oferta e a redução dos preços relativos dos produtos alimentícios. Essa ação facilita o acesso da população a alimentos em quantidade e com qualidade suficiente, sem o comprometimento aos demais direitos sociais básicos. Dentro desta sistemática a Rede de Equipamentos Públicos de Alimentação e Nutrição, incentivam a oferta de refeição de qualidade, a preços acessíveis ou gratuitos, a populações vulneráveis. 


\subsection{Controle na Administração Pública}

Há várias visões de controle na Administração Pública, dentre elas a trazida por Guerra (2005 apud CARLOS, 2009, p. 37) que compila o conceito de controle da Administração Pública, sob o ponto de vista de que trata-se da possibilidade de "verificação, inspeção, exame, tanto pela própria Administração, quanto por Poderes ou qualquer cidadão", amplificando assim o raio de fiscalizadores do processo, com o objetivo de corrigir a "conduta de um gestor público", e assim garantir "uma atuação conforme preceitos e modelos legais, bem como atender às expectativas sociais".

Basicamente, o controle na administração pública brasileira pode ser classificado como institucional e social, sendo o segundo o objeto deste estudo:

- Institucional - formado pelos órgãos de controle externo e interno e pelo Ministério Público;

- Social - formado pela representação da sociedade e que funcione de forma impessoal e no controle dos gastos públicos.

\subsubsection{Controle Social}

O Controle da Sociedade, ou Controle Social, possui aspectos mais minuciosos, sendo, segundo Bobbio; Matteucci; Pasquino (2003), um conjunto de formas de intervenção, disparados por cada sociedade ou grupo social com a finalidade de induzir os próprios membros a se adequarem às normas que a caracterizam, de impedir e desestimular os comportamentos considerados contrários às normas, por fim de restabelecer condições de conformação, também em relação a uma mudança no sistema normativo. Concretizando essa forma de intervenção constituem-se os conselhos sociais de políticas públicas ou simplesmente conselho de políticas sociais.

Assim, para Bittar e Coelho (1994 apud CARLOS, 2009, p. 53), um dos resultados do processo de descentralização do poder estabelecido pela Constituição de 1988, é a formação dos conselhos populares, espaços de intervenção social que se tornam importantes canais institucionais de participação e reconhecimento dos diversos atores sociais participantes diretos ou indiretos na construção de uma 
esfera pública que tem por base fundamental a democracia. Essa mudança no escopo do controle social representa o entendimento consolidado de que seus autores compreendem a dependência existente de canais de participação individuais, combinados com um processo de informação mediante a informatização, transparência e estímulo aos cidadãos para intervirem coletivamente na definição, execução e controle das políticas públicas.

Lembrando que um dos pressupostos da descentralização é a viabilização da proximidade entre governado e governante, o que possibilitaria a população interessada ou parte interessada da política social que as ações dos governos locais fossem acompanhadas de forma sistemática e participativa. Essa abertura de espaço se dá por meio dos Conselhos Municipais, que nada mais são que instâncias criadas para proporcionar à população, por meio do sistema representativo, um acompanhamento e até mesmo a implementação dos programas e das políticas setoriais.

\subsection{Accountability}

O termo accountability pode ser aceito, segundo Matias-Pereira (2007, p. 36) "como o conjunto de mecanismos e procedimentos que induzem os dirigentes governamentais a prestar contas dos resultados de suas ações à sociedade, garantindo dessa forma maior transparência e a exposição pública das políticas públicas."

Entende-se que a vantagem fundamental do accountability é que quanto maior a possibilidade dos cidadãos poderem perceber a atuação em função do interesse coletivo, mais transparente e honesto torna-se o processo de construção da coletividade, levando os decisores governamentais a prestar contas dos resultados de suas ações.

Há dois conceitos importantes de accountability que se diferenciam pela sistemática: o accountability vertical que se caracterizaria pela relação entre a população e as autoridades públicas e que seria representada principalmente pelas eleições, o que se ajustaria ao entendimento Shumpeteriano de participação popular; e o accountability horizontal, que envolve as agências públicas autônomas, para as quais o governo deve prestar contas (SPINELLI; COSTA, 2009). 
Partindo de uma matriz teórica que privilegia a dicotomia estado e sociedade civil, e fazendo um recorte no accountability, tem-se o accountability societal. Partilha-se da ideia de que o controle da sociedade sobre a ação governamental tem peculiaridades que merece distinção à parte dos accountability vertical e horizontal. (SPINELLI; COSTA, 2009). Baseando-se nessa concepção, entende-se que os conselhos de políticas poderiam ser considerados instrumentos de accountability societal, por determinarem uma nova configuração na relação entre Estado e Sociedade.

Faz-se importante o esclarecimento realizado por Abrúcio e Pó (2006, p. 686) que determina que há diferença entre controle e accountability dizendo que eles "não são sinônimos, sendo o primeiro um dos componentes do segundo, embora sejam, num regime democrático, indissociavelmente ligados, porque não há efetivação do accountability sem a utilização de instrumentos institucionais de controle".

Assim, nota-se que a inserção dos conselhos de políticas públicas no ambiente político, em função das prerrogativas atribuídas, tornou-se um mecanismo capaz de proporcionar não somente controle, mas também accountability, pois estas instâncias, devem permitir a participação dos cidadãos no monitoramento e na avaliação das políticas públicas, havendo possibilidade de responsabilização dos agentes públicos em função dos resultados oriundos da ação governamental.

Estudos têm demonstrado que há melhorias na gestão das políticas públicas, principalmente na área de saúde e assistência social, nos locais onde os conselhos são mais atuantes, ou seja, é uma prática que deve ser estimulada, apesar de haver uma dificuldade reconhecida por Carneiro e Costa (2001 apud VIEIRA, 2005, p. 620) na operacionalidade destes conselhos, pois ocorre uma carência, por parte dos representantes da sociedade, de "recursos de conhecimentos, informação e competência especializada". O mesmo autor aponta, ainda, um aspecto perverso de participação de algumas entidades com o objetivo de captar recursos, ou de outro modo (...) "grande parte das entidades busca o conselho na tentativa de conseguirem recursos para financiar suas atividades apresentando uma participação muito tímida, ou mesmo residual". 


\section{MÉTODOS E TÉCNICAS DE PESQUISA}

O método é conjunto de processos fundamentais para se alcançar os fins de uma investigação, sendo o procedimento geral, ou o caminho percorrido em uma investigação (ZANELLA, 2006).

Matias-Pereira (2006) afirma que método por ser aceito como uma sequência de operações feitas pelo intelecto com o objetivo de atingir certo resultado, isto é, a sistematização e ordenação dos pensamentos é o conjunto de procedimentos que permite alcançar a verdade científica. É importante que este método possa ser passível de repetição.

A metodologia de pesquisa tem como objetivo "identificar e analisar os recursos metodológicos, assinalar suas limitações, explicitar seus pressupostos e as consequências de seu emprego." (ASTI VERA, 1974 apud ZANELLA, 2006, p. 20).

O estudo que se apresenta é um estudo de caráter exploratório, quanto à sua tipologia, o qual, segundo Trivinõs (1987 apud ZANELLA, 2009, p. 27), tem a finalidade de ampliar o conhecimento a respeito de um determinado problema, a realidade será explorada para proporcionar um maior conhecimento sobre o problema. Esta tipologia de pesquisa busca examinar um fenômeno para descrevêlo de forma integral ou diferenciá-lo de outro fenômeno (MATIAS-PEREIRA, 2006).

Em relação ao seu contexto, trata-se de um estudo de campo com os gestores da Rede de Equipamentos Públicos de Alimentação e Nutrição, podendo ser caracterizado como um estudo transversal.

Quanto à natureza das variáveis a serem pesquisadas, a pesquisa é classificada como quantitativa. A análise quantitativa será feita utilizando-se os dados coletados e que serão tratados estatisticamente permitindo assim generalizações.

Os dados são primários e secundários, os primeiros coletados por meio de um questionário semi-estruturado e os segundos, provenientes da revisão de literatura feita sobre o assunto. O questionário construído não tem base em nenhuma outra pesquisa realizada anteriormente. 


\subsection{Caracterização da organização, setor ou área}

Este trabalho foi desenvolvido junto à Rede de Equipamentos Públicos de Alimentação e Nutrição - REDESAN que é uma estrutura operacional do Sistema Nacional de Segurança Alimentar e Nutricional - SISAN e é composta por restaurantes populares, cozinhas comunitárias e bancos de alimentos. A REDESAN está sob a coordenação do Ministério do Desenvolvimento Social e Combate à Fome - MDS e é a concretização de parte da estratégia da política nacional de segurança alimentar e nutricional.

\subsection{População e amostra ou participantes do estudo}

A população pesquisada será a de gestores da Rede de Equipamentos Públicos de Alimentação e Nutrição. A pesquisa foi censitária e baseada na quantidade de unidades em funcionamento à época do estudo.

\subsection{Caracterização dos instrumentos de pesquisa}

No questionário aplicado aos gestores (Apêndice A) há uma breve explicação dos objetivos do estudo, dando a garantia do anonimato e do total sigilo acerca de suas respostas individuais. Na sequência, os gestores informaram os dados gerais do equipamento público de alimentação e nutrição; tais dados foram solicitados como forma de garantir que as respostas eram concernentes aos equipamentos da REDESAN, visto que alguns entes possuem iniciativas locais. Após a identificação inicial os gestores responderam a dois blocos de perguntas: o primeiro sobre os Mecanismos de Integração com a Comunidade e o segundo, sobre as Instâncias Institucionais de Controle Social, apesar de o questionário contar com sete perguntas o encadeamento de respostas levava à obrigatoriedade de responder a somente cinco delas. 
Como o instrumento não tinha base em nenhuma outra pesquisa já realizada, foi necessário a construção e validação. A construção foi feita com base nos objetivos gerais e específicos do estudo e a validação foi realizada em duas etapas: com os gestores do âmbito federal dos programas da REDESAN, por meio de reuniões e, posteriormente, com uma amostra dos gestores participantes da pesquisa por meio de correio eletrônico e telefone. Ambas as validações agregaram ajustes ao instrumento inicial e foram eficientes para melhorar a qualidade do instrumento utilizado.

\subsection{Procedimentos de coleta e de análise de dados}

A aplicação foi realizada com o auxílio da ferramenta desenvolvida pela Empresa Google para o aplicativo Google Docs, que permite a criação e aplicação de um formulário em ambiente web. Os gestores receberam um link para o questionário diretamente no seu e-mail e o acessaram por meio de uma página da internet. As respostas foram direcionadas para uma planilha de dados online que podia ser visualizada no aplicativo Google Docs. Quando finalizada a coleta de dados a planilha criada foi exportada como um documento do aplicativo Microsoft Excel.

A análise dos dados foi realizada por meio de estatística descritiva para interpretação dos dados coletados e tal análise gerou gráficos e tabelas. Além de estudar os dados individualmente (análise univariada), foi explorada a relação entre as variáveis estudadas (análise multivariada). Considerando as características da pesquisa e o tamanho da amostra não foram realizados testes de validade estatística. 


\section{RESULTADOS E DISCUSSÃO}

A aplicação do questionário foi realizada do período de 22 de setembro a $1^{\circ}$ de outubro de 2010. Os questionários foram enviados para todos os Equipamentos Públicos de Alimentação e Nutrição da REDESAN que estavam em funcionamento, segundo informado pela Coordenação Geral de Equipamentos Públicos - CGEP no instrumento de Matriz de Informações Sociais do mês de setembro de 2010 (Anexo A). Para as unidades de Cozinha Comunitárias há necessidade de esclarecer que esses equipamentos públicos são divididos em cinco categorias, conforme os tipos de serviços oferecidos (Anexo B), para este estudo não foram consideradas as unidades tipo 1, 2 e 3 por possuírem características específicas de funcionamento que não se adequam ao escopo desta pesquisa.

A população foi constituída por 65 unidades de Banco de Alimentos, 89 unidades de Restaurantes Populares e 136 unidades de Cozinha Comunitárias, perfazendo um total de 290 unidades, conforme Tabela 1. Dos questionários enviados, 78 foram respondidos, o que representa $27,2 \%$ do universo da pesquisa.

Tabela 1: Distribuição por tipos da rede de equipamentos públicos da alimentação e nutrição

\begin{tabular}{l|c|c}
\hline & $\mathbf{n}$ & $\%$ \\
\hline Cozinhas Comunitárias & 136 & 46,9 \\
\hline Banco de Alimentos & 65 & 22,4 \\
\hline Restaurantes Populares & 89 & 30,7 \\
\hline & 290 & 100 \\
\hline
\end{tabular}

Do total de questionários respondidos $(n=78)$ os dados gerais coletados demonstram que 44,9\% ( $n=35)$ dos gestores eram responsáveis por unidades de Cozinha Comunitárias, 28,2\% $(n=22)$ eram responsáveis por Banco de Alimentos e $26,9 \%(n=21)$ por Restaurantes Populares, conforme Tabela 2. 
Tabela 2: Distribuição por tipos frequência de resposta

\begin{tabular}{l|c|c}
\hline & $\mathbf{n}$ & $\%$ \\
\hline Cozinhas Comunitárias & 35 & 44,9 \\
\hline Banco de Alimentos & 22 & 28,2 \\
\hline Restaurantes Populares & 21 & 26,9 \\
\hline & 78 & 100 \\
\hline
\end{tabular}

A maioria dos Equipamentos Públicos de Alimentação e Nutrição 78,2\% $(n=61)$ estão em funcionamento a mais de dois anos, seguido pelos equipamentos que funcionam de 1 a 2 anos 15,4\% $(n=12)$ e somente $6,4 \%(n=5)$ funcionam a menos de 1 ano, conforme Tabela 3.

Tabela 3: Distribuição por tempo de funcionamento

\begin{tabular}{l|c|c}
\hline & $\mathbf{n}$ & $\%$ \\
\hline Mais de 2 anos & 61 & 78,2 \\
\hline De 1 a 2 anos & 12 & 15,4 \\
\hline Menos de 1 ano & 5 & 6,4 \\
\hline & 78 & 100 \\
\hline
\end{tabular}

Quanto à distribuição geográfica, a Região Sudeste aparece com 35,9\% ( $n=28)$, a Região Nordeste com 23,1\% ( $n=18)$, a Região Sul com 21,8\% $(n=17)$, a Região Norte com 16,7\% $(n=13)$ e a Região Centro-Oeste com 2,5\% (n=2), conforme a Tabela 4.

Tabela 4: Distribuição por região geográfica

\begin{tabular}{l|l|l}
\hline & \multicolumn{1}{|c|}{$\mathbf{n}$} & \multicolumn{1}{c}{$\%$} \\
\hline Sudeste & 28 & 35,9 \\
\hline Nordeste & 18 & 23,1 \\
\hline Sul & 17 & 21,8 \\
\hline Norte & 13 & 16,7 \\
\hline Centro-oeste & 2 & 2,5 \\
\hline & 78 & 100 \\
\hline
\end{tabular}


Sobre os mecanismos de integração com a comunidade as principais formas apontadas foram a existência de grupos gestores com $42,3 \%(n=33)$ de frequência e associação de moradores com 35,9\% ( $n=28)$. Foi apontado que não há nenhum tipo de integração com a comunidade por $25,6 \%(n=20)$ dos gestores, enquanto $19,2 \%$ ( $n=15)$ afirmam haver essa integração por meio de consultas públicas e $15,4 \%(n=12)$ por meio de conselhos comunitários. Considerando os gestores que apontaram somente uma forma de integração com a comunidade em 46,1\% ( $n=36)$, observa-se que essa integração ocorre por meio de associação de moradores em 24,4\% ( $n=19)$ dos equipamentos públicos de alimentação e nutrição, por meio de um grupo gestor do equipamento em 12,8\% ( $n=10)$, por meio de conselhos comunitários em 6,4\% $(n=5)$ e por meio de consultas públicas em 2,6\% $(n=2)$, conforme consta no Gráfico 1.

Gráfico 1: Mecanismos de integração com a comunidade dos equipamentos públicos de alimentação e nutrição

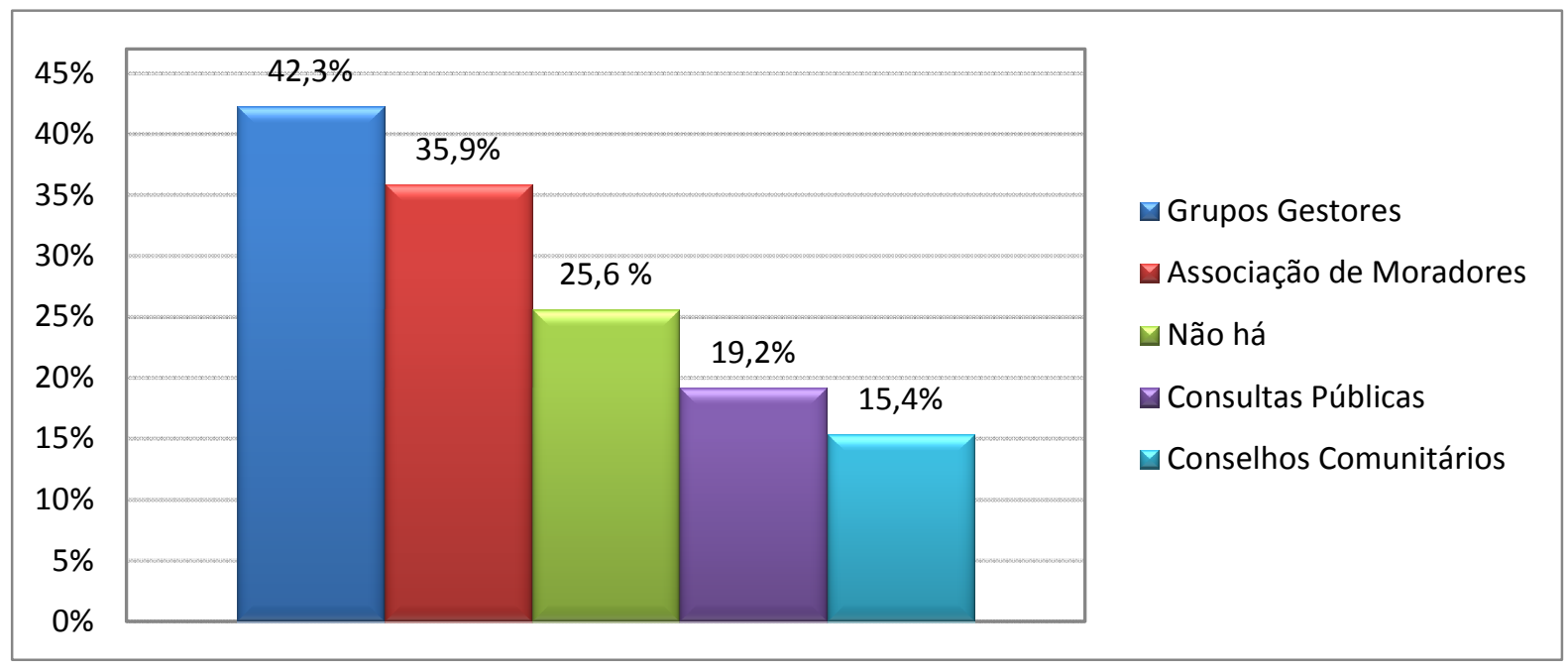

Para além dos espaços oficiais, a presença de integração com a comunidade foi investigada sob o intuito de verificar o aspecto participativo de organizações populares nos equipamentos públicos da REDESAN e, consequentemente, alguns aspectos de presença de capital social, principalmente a variável ligada a participação comunitária. 
Apesar de 25,6\% ( $n=20)$ dos gestores afirmarem não haver tal integração, ainda assim na maioria dos equipamentos nota-se a presença de grupos gestores, associação de moradores e conselhos comunitários, o que leva a entender que "há a abertura, por parte do Estado, de 'poros oficiais', espaços de presença permanente [...] para os diversos segmentos da sociedade em momentos de decisão", tais espaços funcionam como promotor de solidariedade, facilita a consolidação da confiança tornando-se "espaços privilegiados de reflexão e troca de experiências." [...] além de facilitar "o controle social e o desenvolvimento de ações estatais que beneficiem o conjunto da sociedade." (BASTOS; SANTOS; TOVO, 2009, pag.187).

Este cenário aponta para um estoque de capital social ligado aos equipamentos públicos de alimentação de nutrição. Este acúmulo deve ser valorizado e estimulado de forma que as redes de cooperação, entre grupos da sociedade, sejam consolidadas e tragam benefícios que possam garantir o acesso a políticas públicas de qualidade.

Sobre a forma de divulgação das informações públicas - número de pessoas atendidas, número de refeições servidas, ações realizadas pelo EPANS, gastos mensais e investimentos realizados - 67,9\% ( $n=53)$ dos gestores apontaram a internet, 50,0\% ( $n=39)$ apontaram a utilização de jornal local, 42,3\% ( $n=33)$ utilizam mural informativo localizado dentro do equipamento e 28,2\% (n=22) utilizam a rádio local. Chama atenção o percentual de 16,6\% $(n=13)$ dos gestores que declararam que não há divulgação de tais dados, conforme o gráfico 2. Vale esclarecer que estes meios são utilizados de forma combinada, isto é, os equipamentos utilizam dois ou mais meios para a divulgação das informações. Do total de respondentes, $2,8 \%(n=10)$ dos gestores afirmaram que utilizam somente um meio para divulgação dessas informações, sendo eles a internet para 6,4\% $(n=5)$, mural informativo para $3,8 \%(n=3)$ e jornal local para $2,6 \%(n=2)$, conforme o Gráfico 2. 
Gráfico 2: Forma de divulgação das informações públicas dos equipamentos públicos de alimentação e nutrição

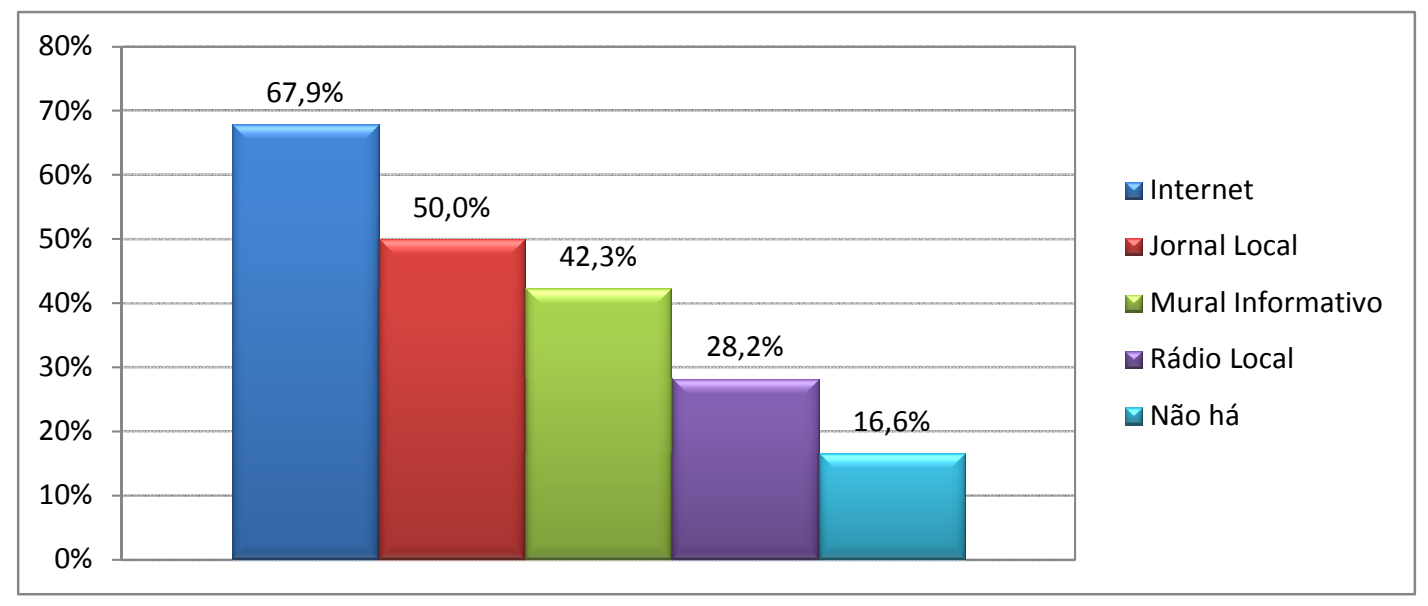

Oliveira (2002, pag. 145) esclarece que para o cidadão fiscalizar de forma competente o Estado, além de se fazer necessário o surgimento do cidadão consciente e organizado, é necessário da parte do Estado "o provimento de informações completas, claras e relevantes a toda a população, expandindo assim o número de controladores e reforçando a legitimidade das políticas públicas". É preocupante sob este ponto de vista o percentual de $16,6 \%$ de EPANS que não fazem nenhum tipo de divulgação deste dado, bem como o frequente uso de mural informativo (42,3\%), pois este tipo de instrumento tem o seu alcance restrito aos utilizadores dos EPANS, não atingindo toda a população, podendo assim não se constituir, de uma forma efetiva, como um instrumento de accountability.

É necessário destacar ainda que, apesar de não terem sido analisadas por este estudo, as informações públicas, para ter caráter de instrumento de accountability, deveriam ser divulgadas "não uma única vez ao ano e em linguagem hermeticamente técnica, mas diariamente e por meio de demonstrativos capazes de - pela fácil compreensão - ampliar cada vez mais o número de controladores" (Oliveira, 2002, pag. 146). Ao cidadão devem ser disponibilizadas informações qualificadas que lhe permitam ter acesso às respostas de questões importantes tanto no papel de usuário como no papel de controlador da administração.

Sobre as instâncias institucionais de controle social, perguntou-se se havia atualmente algum Conselho Municipal em atuação no EPAN. A maioria dos gestores 
afirmou que $\operatorname{sim} 83,3 \%(n=65)$ e 16,7\% $(n=13)$ afirmaram não haver nenhum Conselho Municipal ligado ao equipamento (Gráfico 3), cabe informar que, dos equipamentos que não possuem nenhum conselho em atuação, 38,5\% (n=5) afirmaram na pergunta sobre integração com a comunidade também não haver nenhum tipo de integração.

Dos 65 gestores que afirmaram ter algum Conselho Municipal ligado ao EPAN $64,6 \%(n=42)$ apontaram os conselhos de segurança alimentar municipal, $20,0 \%$ $(n=13)$ os conselhos de segurança alimentar estadual, cabendo aos conselhos de assistência social municipal a responsabilidade por 12,3\% $(n=8)$ dos 65 equipamentos e a outros 3,1\% (n=2), conforme Gráfico 4.

Gráfico 3: Presença de Conselhos ligados ao equipamento público de alimentação e nutrição

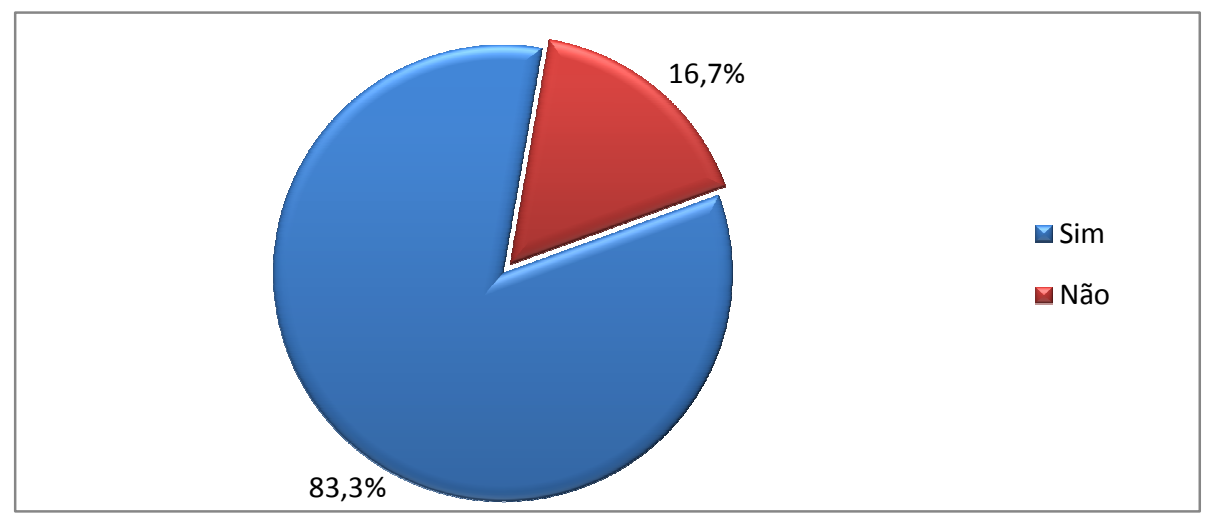

Gráfico 4: Tipos de Conselhos ligados ao equipamento público de alimentação e nutrição tipos de conselhos

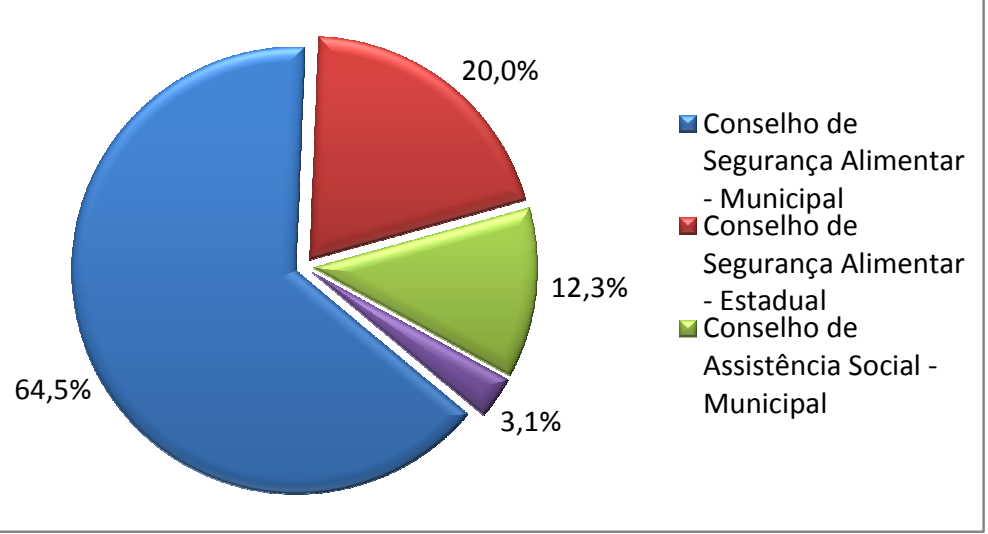


Apesar da crescente consolidação da política de segurança alimentar e do contínuo incentivo a participação social nesta política, percebe-se que ainda existem equipamentos públicos que não podem contar com 0 controle social institucionalizado ou até mesmo nenhum tipo de controle social. Além disso, nota-se ainda a presença de Conselhos de Assistência Social que, na maioria das vezes, já estão sobrecarregados com outras demandas de sua área finalística e não podem prestar o apoio necessário ao desenvolvimento da política de segurança alimentar e nutricional. Ademais, apesar dessas duas instâncias de controle coexistirem na execução da política, possuem como características estruturais, composição, representação e natureza diferentes, conforme demonstrado no Quadro 1, o que poderá refletir em direcionamentos divergentes na execução da política.

Quadro 1: Principais características dos conselhos ligados aos Equipamentos Públicos de Alimentação e Nutrição da REDESAN.

\begin{tabular}{|l|l|l|l|}
\hline \multicolumn{1}{|c|}{ Conselho } & \multicolumn{1}{|c|}{ Composição } & $\begin{array}{c}\text { Representação dos atores } \\
\text { não-governamentais }\end{array}$ & $\begin{array}{c}\text { Natureza dos } \\
\text { Conselhos }\end{array}$ \\
\hline CONSEA & Não paritário & $\begin{array}{l}\text { Vinculada com indicação das } \\
\text { entidades }\end{array}$ & Consultivo \\
\hline CNAS & Paritário bipartite & Vinculada com eleições & Deliberativo \\
\hline
\end{tabular}

Fonte: Disoc/lpea, a partir de critérios propostos por Draibe (SILVA, JACCOUD; BEGHIN, 2005)

Aos gestores que afirmaram não possuir atualmente nenhum Conselho ligado ao equipamento $(n=13)$ perguntou-se qual o conselho municipal que aprovou 0 projeto de implantação do equipamento público de alimentação e nutrição à época do edital de seleção. A maioria $61,5 \%(n=8)$ apontou o conselho municipal de assistência social e $23,1 \%(n=3)$ o conselho municipal de segurança alimentar, foram apontadas ainda outras instâncias 7,7\% (n=1) e 7,7\% (n=1) afirmou não se recordar, conforme demonstrado no Gráfico 5. 
Gráfico 5: Conselhos ligados a aprovação da ata do projeto do equipamento público de alimentação e nutrição

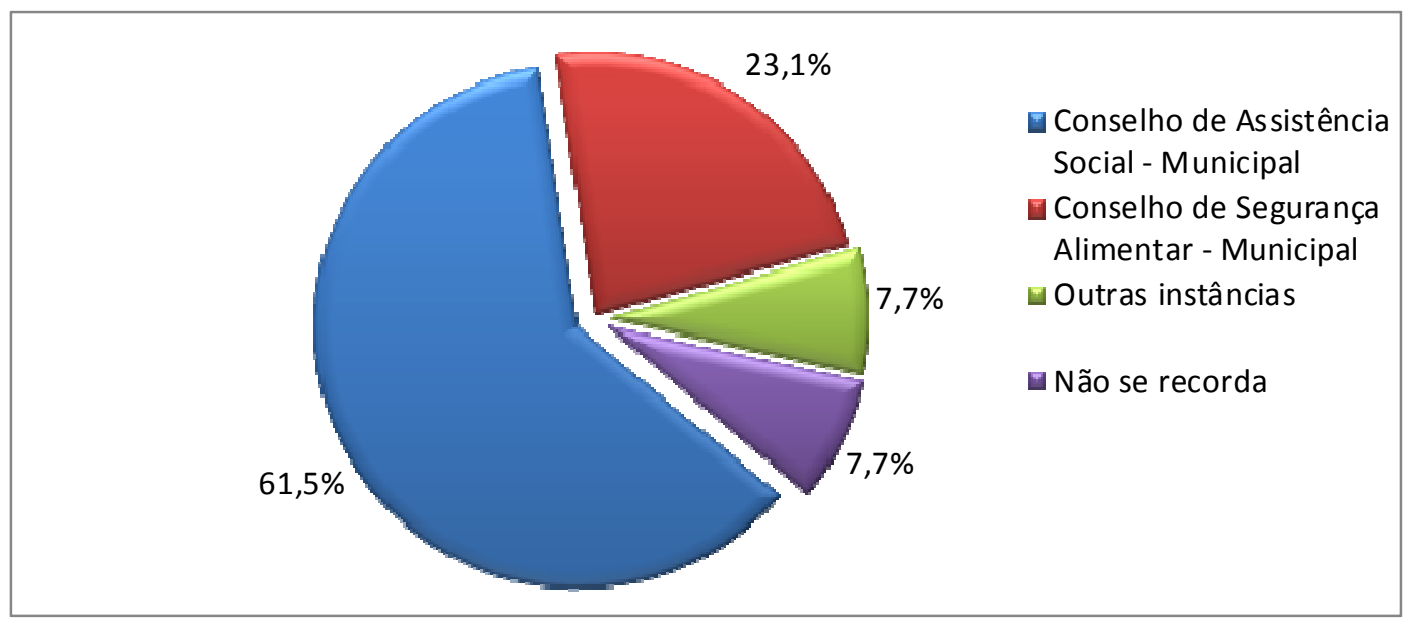

Procurando perceber qual o tipo de atuação dos conselhos institucionais, perguntou-se sobre atuação dessas instâncias junto aos equipamentos. Dos gestores respondentes, $66,7 \%(n=52)$ diz que há tal participação na fiscalização dos resultados, 58,9\% $(n=46)$ disse que o conselho está presente no cotidiano do EPAN, ajudando a planejar as ações, $57,7 \%(n=45)$ afirma que o conselho participou na etapa de planejamento dos EPANS, 50,0\% ( $n=39)$ apontou esta participação na etapa de implantação (obras, aquisição de equipamentos e utensílios) e somente $2,6 \%(n=2 \%)$ afirmou que os conselhos só atuam em casos de denúncias, conforme Gráfico 6.

Gráfico 6: Atuação dos conselhos ligados aos equipamentos públicos de alimentação e nutrição

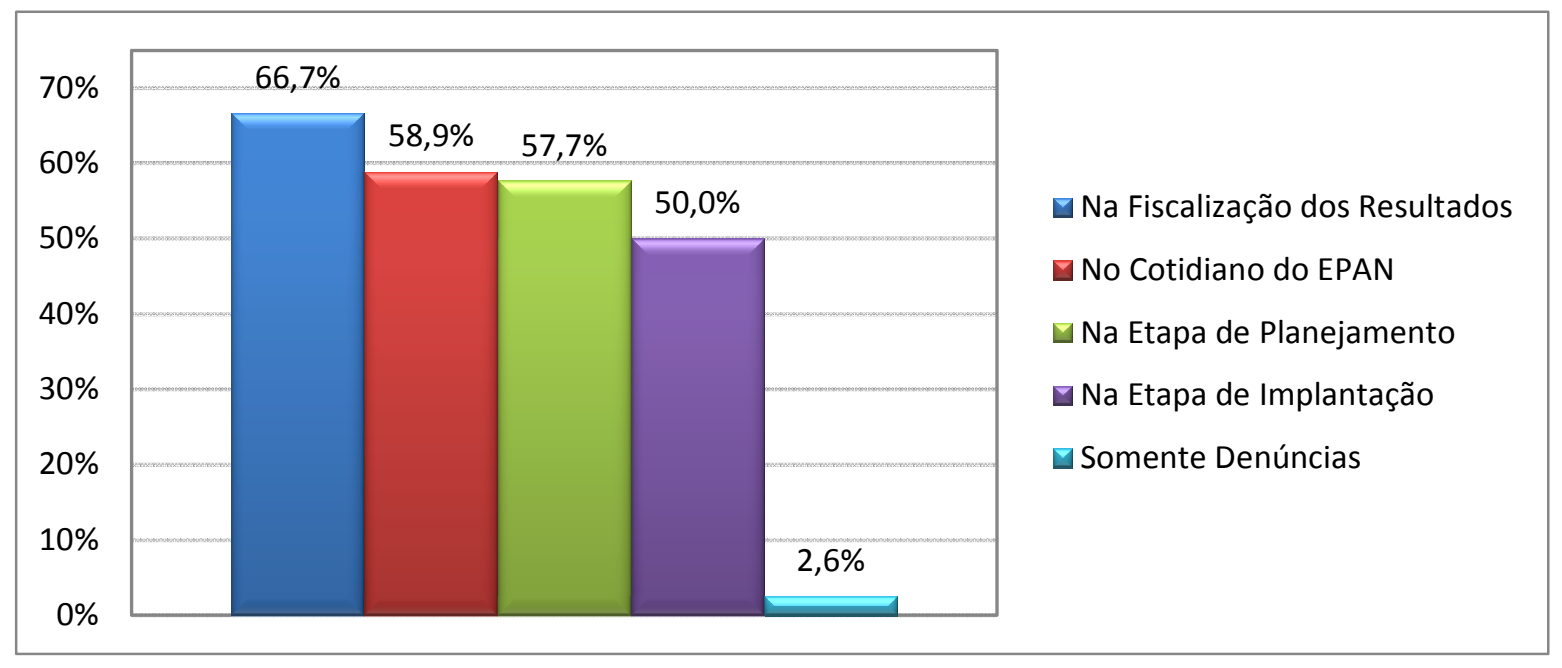


Realizando correlações a partir dos dados levantados somente em 29,2\% $(n=19)$ dos EPANS que declararam atuação do conselho, nota-se uma atuação ampla que vai das etapas iniciais: de planejamento e execução física, até as etapas ligadas ao funcionamento: atuação no cotidiano, ajudando a planejar as ações e na fiscalização dos resultados.

Faz-se incoerente a afirmação de que há um conselho municipal atuando no EPAN quando tal conselho é relacionado como responsável somente por atividades ligadas às etapas iniciais do projeto - implantação e planejamento como afirmam $10,8 \%(n=7)$ dos gestores. Ou ainda, são apontados como atuantes somente na fiscalização dos resultados ou no caso de denúncias, como ocorrem em $6,2 \%$ $(n=4)$ e $1,5 \%(n=1)$ respectivamente.

Dos gestores que afirmaram não haver nenhum conselho ligado ao equipamento público $(n=13)$, a maioria $84,6 \%(n=11)$ declarou a atuação do conselho apontado como responsável pela aprovação do projeto na etapa de planejamento e $53,8 \%(n=7)$ na etapa de implantação do equipamento, isto é, antes do início do funcionamento do equipamento público de alimentação e nutrição. Ainda neste grupo 7,7\% (n=1) apontou atuação na fiscalização dos resultados, 7,7\% ( $n=1)$ em caso de denúncia e 7,7\% ( $n=1)$ não soube responder. Percebe-se assim que a obrigatoriedade de aprovação da proposta por um conselho gestor não garante a continuidade de acompanhamento nas demais etapas do programa, principalmente nas etapas de funcionamento onde seria necessária a atuação do controle social para garantir a efetividade da política pública. 


\section{CONCLUSÕES E RECOMENDAÇÕES}

O principal objetivo do trabalho era avaliar o nível de participação e controle social na Rede de Equipamentos Públicos de Alimentação e Nutrição. Tal participação, quando efetivamente existente, contribui não só para uma maior inclusão da sociedade civil no processo decisório das ações existentes nos espaços públicos, como também para desenvolver o controle social sobre a formulação e gestão de políticas públicas.

Sabe-se que muito do que ocorre nas políticas públicas não perpassa os conselhos, porém sabe-se que é fundamental a presença desses espaços, que, se legítimos, condicionam a atuação e as estratégias dos diversos componentes e atores das políticas (SILVA; JACCOUD; BEGHIN, 2005).

Tomando o sentido da palavra nível como situação que se apresenta, o estudo demonstra que há a presença de conselhos nos equipamentos públicos, o que, numa sistemática perfeita, mas também como utopia possível, se constituiria como importantes mecanismos para viabilizar e proporcionar uma aproximação maior entre as demandas da sociedade e a ação governamental.

Considerando outros aspectos da participação social, que vão além dos conselhos institucionais, e buscando outros elementos para a estruturação de mecanismos que garantam o accountability societal, o estudo demonstra que há a incorporação de novos atores, tais como associação, conselhos gestores e conselhos comunitários que nada mais são que o resultado da busca, para sancionar ou forçar a administração pública a reagir como resultado do exercício do controle social. Esta abertura deve ser valorizada e ampliada, cabendo ao Estado "propiciar a incorporação de amplos setores sociais com rapidez, buscando suplantar uma herança social excludente, através de políticas que tornem equânime o acesso aos bens e aos serviços públicos, qualificando as relações entre Estado e sociedade" (TORRES, 2004 apud BASTOS; SANTOS; TOVO, 2009, pag.187).

Sobre as formas de divulgação das informações públicas da rede de equipamentos públicos de alimentação e nutrição, chama atenção os resultados obtidos em relação à forma de divulgação das informações sendo importante o dado 
de que existem equipamentos que não realizam tal divulgação e que um dos principais meios de divulgação são os murais localizados dentro dos equipamentos. As informações públicas para serem utilizadas de forma efetiva como mecanismo de accountability devem ter grande amplitude e publicidade, os murais informativos atingem somente o público que frequenta os equipamentos não garantindo essa amplitude. Sob este aspecto é importante comentar a constatação feita por OLIVEIRA (2002, pag. 145) de "que a abaixa credibilidade por que passam hoje quase todas as instituições no Brasil é decorrente em boa parte de seu déficit de accountability". Seria positivo que fosse estimulada a divulgação de dados públicos por outros meios, e que tais dados fossem, além de frequentes, de simples entendimento e reprodução, auditáveis devendo para isso estarem baseados em instrumentos internos de acompanhamento.

A atuação dos conselhos junto à rede de equipamentos públicos de alimentação e nutrição apresenta-se coerente com o esperado para as instâncias de controle social, realizando sua função fiscalizatória das ações dos equipamentos públicos e também participando da construção das atividades cotidianas. Tal conformação deve ser estimulada pois muitas vezes o planejamento estratégico pensado para os equipamentos públicos precisam ir além da função principal de fornecimento de alimentação e combate ao desperdício e devendo as ações do equipamento ter a interface com outras ações de combate à insegurança alimentar, retomando seus aspectos sociais e de inclusão, e interferindo na realidade local a ponto de mudar o panorama de insegurança alimentar existente.

Para além dos aspectos positivos de controle social que foram encontrados, um dado importante do estudo é a existência de equipamentos públicos que não possuem nenhum conselho ligado à sua gestão. Este resultado se apresenta como uma problemática no desenvolvimento da política, pois entende-se que a exigência feita no início do processo não garante a continuação das atividade a ser exercida pelos conselhos que aprovam as propostas, nas demais etapas do programa. Fazse necessário destacar que esta situação se apresenta mais constante quando o conselho aprovador da proposta inicial é da área de assistência social.

A baixa adesão dos gestores à participação na pesquisa demonstra que há necessidade de amadurecimento sobre a importância de se monitorar e avaliar as ações dos equipamentos públicos da REDESAN. Recomenda-se que o estudo seja 
ampliado e que outros instrumentos sejam incluídos na análise, ampliando o debate sobre a situação do controle social nos equipamentos e sobre o tipo e a qualidade das informações disponibilizadas aos cidadãos, o que poderia gerar na área de administração pública subsídios para discussão do grau de transparência na gestão pública e seu consequente aperfeiçoamento. Sobre o acúmulo de capital social que parece estar ocorrendo com a abertura à participação de outras instâncias que não institucionais, recomenda-se, além do estímulo a esse comportamento, a cessão de igualdade de oportunidade para influir no processo de tomada de decisões, de forma a assegurar que as demandas sociais sejam ouvidas e atendidas, vale a pena ressaltar que o estoque de capital social e associativismo tem sido elemento de discussão em diversas áreas que seguem linhas mais modernas de administração pública.

Como se percebe, a discussão é extensa, e abrange outros elementos que neste estudo foram apenas superficialmente levantados como, por exemplo, o caráter consultivo dos conselhos de segurança alimentar e nutricional, discussão de cunho social e de direito, mas também administrativa, visto que tem haver com normativos a atribuições legais e suas conformações.

Conclui-se que apesar das limitações e das dificuldades que são enfrentadas pelos conselhos institucionais de políticas sociais, não se pode minimizar sua contribuição para a ampliação da cidadania. Sendo a política nacional de segurança alimentar recente frente às outras políticas como de saúde e assistência social, esta participação é um processo ainda em construção que assinala possibilidades concretas de desenvolvimento de novas arenas públicas de intermediação de interesses. Apesar disso, os benefícios da participação social efetiva foram empiricamente observados na rede de equipamentos públicos de alimentação e nutrição. 


\section{REFERÊNCIAS}

ABRÚCIO, F. L.; PÓ, M. V. Desenho e funcionamento dos mecanismos de controle e accountability das agências reguladoras brasileiras: semelhanças e diferenças. Revista Brasileira de Administração Pública, Rio de Janeiro, v. 40. n. 4, jul./ago. 2006. Disponível em:<http://www.scielo.br/pdf/rap/v40n4/31601.pdf>. Acesso em 11 abr. 2010

BASTOS, Francisco Avelar; SANTOS, Everton; TOVO, Maximiano Ferreira. Capital Social e Sistema Único de Saúde (SUS) no Brasil. Saude soc., São Paulo, v. 18, n. 2, jun.2009.

BOBBIO, N.; MATTEUCI, N.; PASQUINO, G (orgs). Dicionário de Política. CDROM. Editora UnB: 2003.

BRASIL. Constituição da República Federativa do Brasil. Brasília: Senado Federal. 1988.

. Lei 11.346, de 15 de setembro de 2006 - Lei Orgânica de Segurança Alimentar e Nutricional (LOSAN). Brasília: Diário Oficial da União. 2006. Disponível em:<http://www.planalto.gov.br/ccivil 03/ Ato2004-2006/2006/Lei/L11346.htm>. Acesso em 10 abr. 2010.

.CONSEA - Conselho Nacional de Segurança Alimentar. Construção do Sistema e da Política de Nacional de Segurança Alimentar e Nutricional: a experiência brasileira. Brasília: 2009a.

Políticas Sociais: acompanhamento e análise. Apresentação. Vinte Anos da Constituição Federal. Introdução. n. 17. IPEA: Brasília. 2009b.

Comunicados da Presidência $\mathbf{n}^{\circ}$ 38. Pobreza, Desigualdade e Políticas Públicas. Brasília: IPEA, 2010. Disponível em: $<$ http://www.ipea.gov.br/sites/000/2/comunicado presidencia/100112Comunicado38. pdf. >. Acesso em 20 abr. 2010.

CARLOS, F. A. CONTROLE SOCIAL NO ÂMBITO MUNICIPAL: Um estudo sobre a utilidade dos relatórios da Controladoria Geral da União (CGU) na percepção dos conselheiros de políticas sociais no Estado de Pernambuco. Recife, 2009. 174p. 
Dissertação (Mestrado em Contabilidade). Universidade Federal de Pernambuco. 2009.

CARneIRO, C. B. L. Conselhos de Políticas Públicas: desafios para sua institucionalização. In: Políticas Públicas. Coletânea - Vol 1. p. 149-166. Brasília: ENAP, 2006.

CASTRO, J. A; RIBEIRO, J. A. C. As Políticas Sociais e a Constituição de 1988: Conquistas e Desafios. In: Políticas Sociais: acompanhamento e análise. Vinte Anos da Constituição Federal. Vol. 1, n. 17. IPEA: Brasília. 2009.

IBASE. Repercussões do Programa Bolsa Família na segurança alimentar e nutricional: relatório síntese. Rio de Janeiro: 2008.

JACCOUD, L.; EL-MOOR HADJAB, P. D.; CHAIBUB, J. R. Assistência Social e Segurança Alimentar: entre novas trajetórias, velhas agendas e recentes desafios (1988-2008). In: Políticas Sociais: acompanhamento e análise. Vinte Anos da Constituição Federal. Introdução. n. 17. IPEA: Brasília. 2009.

MATIAS-PEREIRA, J. Manual de Gestão Pública Contemporânea. São Paulo: Nobel, 2007.

2006.

Metodologia Científica: Manual de Pesquisa Científica. Brasília. UnB:

OLIVEIRA, A. Controle Social: perspectivas para a fiscalização popular da administração pública no Brasil. In: Prêmio Serzedello Corrêa 2001: Monografias Vencedoras: Perspectivas para o Controle Social e a Transparência da Administração Pública/Tribunal de Contas da União. Brasília: TCU, Instituto Serdello Corrêa, 2002.

SARAVIA. E. Introdução à Teoria da Política Pública. In: Políticas Públicas. Coletânea - Volume 1. p. 21-41. Brasília: ENAP, 2006.

SILVA, F. B.; JACCOUD, L.; BEGHIN, N. Políticas Sociais no Brasil: participação social, conselhos e parcerias. In: "Questão Social e Políticas Sociais no Brasil Contemporâneo”. Brasília: Ipea, 2005. Capítulo 8. 
SPINELLI, M. V.; COSTA, B. L. D. Participação, accountability e desempenho institucional: o caso dos Conselhos de Controle Social do Programa Bolsa Família nos pequenos municípios brasileiros. XXII Concurso del CLAD sobre Reforma del Estado y Modernizacion de la Administración Pública. Anais, p. 1-44. Caracas, 2009.

VIEIRA, J. B. Estado, sociedade civil e accountability. Ensaios FEE. n. 1. v. 26, p. 605-626, jun. 2005.

ZANELLA, L. C. H. Metodologia da pesquisa. Apostila elaborada para o curso de administração na modalidade a distância. Brasília: UnB, 2009. 


\section{APÊNDICES}




\section{Apêndice A - Questionário}

\section{Apresentação da Pesquisa}

\section{Prezado(a) Gestor(a):}

Além de Servidora do MDS e técnica responsável pelo Programa Cozinhas Comunitárias, sou aluna do curso de Graduação em Administração da Universidade de Brasília e estou desenvolvendo um projeto de pesquisa sobre o Nível de Controle Social nos Equipamentos Públicos de Alimentação e Nutrição. O objetivo é dar subsídios técnicos à minha monografia de conclusão de curso.

A sua aplicação está direcionada aos gestores dos EPANs - Equipamentos Públicos de Alimentação e Nutrição em funcionamento, são somente 5 (cinco) perguntas simples, que são respondidas em menos 5 minutos.

As informações serão analisadas desconsiderando-se a possível identificação dos respondentes, tendo em vista a manutenção do sigilo e do anonimato da pesquisa.

Por favor, mesmo que você seja gestor de mais de um equipamento responda com relação a somente um deles por questionário, neste caso você pode responder mais de uma vez o questionário.

Muito obrigada por sua colaboração!!

Katia Francisco de Lima

\section{Questionário}

Dados Gerais do Equipamento Público de Alimentação e Nutrição (EPAN):

Tipo de EPAN:

( ) Restaurante Popular

( ) Banco de Alimentos

( ) Cozinha Comunitária

Endereço:

Município:

Bairro:

CEP:

Tempo de Funcionamento do EPAN:

( ) Menos de 1 ano ( ) 1 a 2 anos ( ) mais de 2 anos

\section{Sobre os Mecanismos de Integração com a Comunidade:}

1) Quais os mecanismos de integração com a comunidade?

( ) Associação de Moradores

( ) Conselho Comunitário (não considerar Conselhos Institucionais: COMSEA, CMAS, etc) 
( ) Grupo Gestor do Equipamento Público de Alimentação e Nutrição

( ) Consultas Públicas

( ) Não há

2) Qual o método de divulgação das informações públicas* do equipamento? (Marcar todas as existentes)

( ) Mural Informativo no Local

( ) Jornal Local

( ) Internet (site, blog, redes sociais)

( ) Rádio Local

( ) Não há

Sobre as Instâncias Institucionais de Controle Social:

3) Atualmente há algum Conselho Municipal que tenha atuação no Equipamento de Alimentação e Nutrição ?

( ) $\operatorname{sim}($ ) não (pular para 5)

4) Se sim, qual o conselho ? (Citar somente o principal - Escrever sigla e nome do Conselho por extenso)

5) Se não, já existiu algum Conselho Municipal que atuava no Equipamento de Alimentação e Nutrição (citar o Conselho que aprovou a ata de aprovação do projeto)?

( ) $\operatorname{sim}($ ) não

6) Qual conselho ? (Citar somente o principal - Escrever sigla e nome do Conselho por extenso)

7) Aponte um ou mais momentos em que ocorre ou ocorreu a atuação do Conselho apontado:

( ) Na etapa de planejamento do EPAN;

( ) Na etapa de implantação (obras, aquisição de equipamentos e utensílios) do EPAN;

( ) No cotidiano do EPAN, ajudando a planejar as ações;

( ) Na fiscalização dos resultados;

( ) Somente em caso de denúncias; 


\section{ANEXOS}




\section{Anexo A - Listagem de Equipamentos Públicos de Alimentação e Nutrição da REDESAN em Funcionamento}

\begin{tabular}{|c|c|c|c|c|}
\hline UF & Município & $\begin{array}{l}\text { Banco de } \\
\text { Alimentos }\end{array}$ & $\begin{array}{l}\text { Restaurantes } \\
\text { Populares }\end{array}$ & $\begin{array}{c}\text { Cozinhas } \\
\text { Comunitárias }\end{array}$ \\
\hline $\mathrm{AC}$ & Rio Branco & & 1 & \\
\hline $\mathrm{AL}$ & Arapiraca & & 1 & \\
\hline $\mathrm{AL}$ & Maceió & & 1 & \\
\hline AM & Manaus & & 2 & \\
\hline $\mathrm{BA}$ & Aratuípe & & & 1 \\
\hline $\mathrm{BA}$ & Camaçari & 1 & & \\
\hline $\mathrm{BA}$ & Feira de Santana & & 1 & \\
\hline $\mathrm{BA}$ & Itabuna & & 1 & \\
\hline $\mathrm{BA}$ & Jequié & & 1 & \\
\hline $\mathrm{BA}$ & Juazeiro & 1 & 1 & \\
\hline $\mathrm{BA}$ & Lauro de Freitas & 1 & 1 & 1 \\
\hline $\mathrm{BA}$ & Paulo Afonso & 1 & 1 & \\
\hline $\mathrm{BA}$ & Serra Preta & & & 1 \\
\hline $\mathrm{CE}$ & Alto Santo & & & 1 \\
\hline CE & Aquiraz & & & 1 \\
\hline $\mathrm{CE}$ & Bela Cruz & & & 1 \\
\hline CE & Caucaia & 1 & & \\
\hline $\mathrm{CE}$ & Crateús & & & 1 \\
\hline CE & Crato & & 1 & \\
\hline CE & Juazeiro do Norte & 1 & 1 & \\
\hline $\mathrm{CE}$ & Maracanaú & & 1 & 5 \\
\hline $\mathrm{CE}$ & Missão Velha & & & 1 \\
\hline $\mathrm{CE}$ & Orós & & & 1 \\
\hline $\mathrm{CE}$ & Pacatuba & & & 3 \\
\hline CE & Quixadá & 1 & & \\
\hline CE & São João do Jaguaribe & & & 1 \\
\hline CE & Sobral & & 1 & \\
\hline $\mathrm{CE}$ & Tejuçuoca & & & 1 \\
\hline DF & Brasília & & 1 & \\
\hline ES & Ibitirama & & & 1 \\
\hline ES & Ponto Belo & & & 1 \\
\hline ES & Vitória & 1 & & \\
\hline GO & Goiânia & 1 & 1 & \\
\hline GO & Paraúna & & & 1 \\
\hline GO & Quirinópolis & & & 1 \\
\hline MA & Codó & & 1 & \\
\hline MA & Formosa da Serra Negra & & & 1 \\
\hline MA & Imperatriz & 1 & 1 & \\
\hline
\end{tabular}




\begin{tabular}{|c|c|c|c|c|}
\hline UF & Município & $\begin{array}{l}\text { Banco de } \\
\text { Alimentos }\end{array}$ & $\begin{array}{c}\text { Restaurantes } \\
\text { Populares }\end{array}$ & $\begin{array}{c}\text { Cozinhas } \\
\text { Comunitárias }\end{array}$ \\
\hline MA & Santana do Maranhão & & & 1 \\
\hline MA & São Bernardo & & & 1 \\
\hline MA & São José de Ribamar & & & 1 \\
\hline MG & Açucena & & & 1 \\
\hline MG & Alfenas & & 1 & \\
\hline MG & Belo Horizonte & 1 & 4 & \\
\hline MG & Betim & 1 & 1 & \\
\hline MG & Buenópolis & & & 1 \\
\hline MG & Buritis & & & 1 \\
\hline MG & Chapada Gaúcha & & & 1 \\
\hline MG & Comercinho & & & 1 \\
\hline MG & Cônego Marinho & & & 1 \\
\hline MG & Contagem & 2 & & 2 \\
\hline MG & Divinópolis & & 1 & \\
\hline MG & Formiga & 1 & & \\
\hline MG & Formoso & & & 1 \\
\hline MG & Governador Valadares & & 1 & \\
\hline MG & Ipatinga & & 1 & \\
\hline MG & Janaúba & 1 & & \\
\hline MG & Joanésia & & & 1 \\
\hline MG & Lagoa da Prata & & & 6 \\
\hline MG & Leopoldina & & & 3 \\
\hline MG & Marliéria & & & 1 \\
\hline MG & Minas Novas & & & 1 \\
\hline MG & Montes Claros & & 1 & \\
\hline MG & Novorizonte & & & 1 \\
\hline MG & Patos de Minas & & 1 & \\
\hline MG & Pedra Azul & & & 1 \\
\hline MG & Poços de Caldas & & 1 & \\
\hline MG & Presidente Olegário & & & 1 \\
\hline MG & Ribeirão das Neves & 1 & & \\
\hline MG & Sabará & 1 & & 3 \\
\hline MG & Santos Dumont & & & 3 \\
\hline MG & São João del Rei & & 1 & \\
\hline MG & Sete Lagoas & & 1 & \\
\hline MG & Taiobeiras & & & 3 \\
\hline MG & Três Marias & & & 1 \\
\hline MG & Ubá & 1 & & \\
\hline MG & Uberaba & 1 & & \\
\hline MG & Uberlândia & 1 & & \\
\hline MG & Unaí & & & 3 \\
\hline MG & Varginha & 1 & 1 & \\
\hline
\end{tabular}




\begin{tabular}{|c|c|c|c|c|}
\hline UF & Município & $\begin{array}{l}\text { Banco de } \\
\text { Alimentos }\end{array}$ & $\begin{array}{l}\text { Restaurantes } \\
\text { Populares }\end{array}$ & $\begin{array}{c}\text { Cozinhas } \\
\text { Comunitárias }\end{array}$ \\
\hline MS & Campo Grande & 1 & & \\
\hline MT & Cuiabá & 1 & 1 & \\
\hline MT & Várzea Grande & & 1 & \\
\hline PA & Ananindeua & & 1 & \\
\hline PA & Belém & & 1 & \\
\hline PA & Santarém & & 1 & \\
\hline $\mathrm{PB}$ & Bayeux & & 1 & \\
\hline PB & Cajazeiras & 1 & & \\
\hline PB & Campina Grande & 1 & 2 & 6 \\
\hline PB & João Pessoa & 1 & & \\
\hline PB & Patos & 1 & 1 & \\
\hline PB & Piancó & & & 1 \\
\hline PB & Poço Dantas & & & 1 \\
\hline PB & Rio Tinto & & & 1 \\
\hline PB & Santa Rita & & 1 & \\
\hline $\mathrm{PE}$ & Betânia & & & 1 \\
\hline PE & Buíque & & & 1 \\
\hline $\mathrm{PE}$ & Ipubi & & & 1 \\
\hline PE & Orocó & & & 1 \\
\hline PE & Petrolina & & 1 & \\
\hline PE & Recife & 1 & 1 & \\
\hline $\mathrm{PE}$ & Surubim & 1 & & \\
\hline $\mathrm{PI}$ & Parnaíba & & 1 & \\
\hline $\mathrm{PI}$ & Teresina & & 2 & \\
\hline PR & Bom Sucesso & & & 1 \\
\hline $\mathrm{PR}$ & Colombo & & 1 & \\
\hline PR & Curitiba & & 3 & \\
\hline $\mathrm{PR}$ & Foz do Iguaçu & 1 & & \\
\hline $\mathrm{PR}$ & Londrina & 1 & & \\
\hline $\mathrm{PR}$ & Maringá & & 1 & \\
\hline $\mathrm{PR}$ & Nova Cantu & & & 1 \\
\hline $\mathrm{PR}$ & Paranaguá & & 1 & \\
\hline PR & Ponta Grossa & 1 & & \\
\hline $\mathrm{PR}$ & Toledo & & 1 & \\
\hline PR & Ubiratã & & & 1 \\
\hline PR & Umuarama & 1 & & \\
\hline RJ & Mesquita & 1 & & 1 \\
\hline RJ & Niterói & 1 & & \\
\hline RJ & Nova Iguaçu & 1 & & \\
\hline RJ & Petrópolis & & 1 & 3 \\
\hline RJ & Rio de Janeiro & & 5 & \\
\hline RJ & São Gonçalo & & & 10 \\
\hline
\end{tabular}




\begin{tabular}{|c|c|c|c|c|}
\hline UF & Município & $\begin{array}{l}\text { Banco de } \\
\text { Alimentos }\end{array}$ & $\begin{array}{l}\text { Restaurantes } \\
\text { Populares }\end{array}$ & $\begin{array}{c}\text { Cozinhas } \\
\text { Comunitárias }\end{array}$ \\
\hline RJ & Volta Redonda & 1 & & \\
\hline $\mathrm{RN}$ & Jucurutu & & & 1 \\
\hline RN & Lagoa de Pedras & & & 1 \\
\hline $\mathrm{RN}$ & Natal & 1 & & \\
\hline $\mathrm{RN}$ & Serra Negra do Norte & & & 1 \\
\hline RO & Ariquemes & 1 & & \\
\hline $\mathrm{RR}$ & Boa Vista & & 2 & \\
\hline RS & Barra do Quaraí & & & 1 \\
\hline $\mathrm{RS}$ & Caxias do Sul & 1 & 1 & \\
\hline $\mathrm{RS}$ & Entre ljuís & & & 1 \\
\hline RS & Gravataí & 1 & & \\
\hline RS & Pelotas & & 1 & \\
\hline RS & Porto Alegre & & 1 & 10 \\
\hline RS & Santa Cruz do Sul & & & 3 \\
\hline RS & Santa Maria & 1 & 2 & 1 \\
\hline $\mathrm{RS}$ & Santo Ângelo & 1 & & 1 \\
\hline RS & Uruguaiana & 1 & 1 & \\
\hline SC & Blumenau & 1 & & \\
\hline SC & Chapecó & 1 & 1 & 1 \\
\hline SC & Joinville & & 1 & \\
\hline SC & Mafra & 1 & & \\
\hline SE & Japaratuba & & & 1 \\
\hline SE & Laranjeiras & & & 1 \\
\hline SE & $\begin{array}{l}\text { Nossa Senhora do } \\
\text { Socorro }\end{array}$ & & 1 & \\
\hline SP & Araçatuba & & 1 & \\
\hline SP & Araraquara & 1 & 1 & \\
\hline SP & Atibaia & & 1 & \\
\hline SP & Campinas & 1 & & \\
\hline SP & Cubatão & & & \\
\hline SP & Diadema & 1 & 2 & \\
\hline SP & E. T. de Embu das Artes & 1 & & \\
\hline SP & Ferraz de Vasconcelos & & 1 & \\
\hline SP & Guarujá & & 1 & \\
\hline SP & Guarulhos & 1 & 1 & \\
\hline SP & Hortolândia & 1 & & 1 \\
\hline SP & Indiaporã & & & 1 \\
\hline SP & Itanhaém & 1 & & \\
\hline SP & Itaquaquecetuba & 1 & & 1 \\
\hline SP & Jandira & 1 & 1 & \\
\hline SP & Marília & & & 1 \\
\hline SP & Mauá & 1 & 1 & \\
\hline SP & Mendonça & & & 1 \\
\hline
\end{tabular}




\begin{tabular}{|c|c|c|c|c|}
\hline UF & Município & $\begin{array}{l}\text { Banco de } \\
\text { Alimentos }\end{array}$ & $\begin{array}{c}\text { Restaurantes } \\
\text { Populares }\end{array}$ & $\begin{array}{c}\text { Cozinhas } \\
\text { Comunitárias }\end{array}$ \\
\hline SP & Osasco & 1 & & \\
\hline SP & Porto Ferreira & & & 1 \\
\hline SP & Ribeirão Corrente & & & 1 \\
\hline SP & Ribeirão Preto & 1 & & \\
\hline $\mathrm{SP}$ & Rio Claro & 1 & & \\
\hline SP & Santo André & 1 & & \\
\hline SP & São Carlos & 1 & 2 & 1 \\
\hline $\mathrm{SP}$ & São José do Rio Preto & 1 & & \\
\hline SP & São Paulo & & 1 & \\
\hline SP & São Vicente & & 1 & \\
\hline SP & Suzano & 1 & 1 & \\
\hline TO & Araguaçu & & & 1 \\
\hline TO & Araguaína & & 1 & \\
\hline TO & Araguatins & & & 1 \\
\hline TO & Aguiarnópolis & & & 1 \\
\hline TO & Axixá do Tocantins & & & 1 \\
\hline TO & Brejinho de Nazaré & & & 1 \\
\hline TO & Darcinópolis & & & 1 \\
\hline TO & Dianópolis & & & 1 \\
\hline TO & Paraíso do Tocantins & & & 1 \\
\hline TO & Porto Nacional & & & 1 \\
\hline TO & Silvanópolis & & & 1 \\
\hline TO & Xambioá & & & 1 \\
\hline \multicolumn{2}{|c|}{ Total de unidades em funcionamento } & 65 & 89 & 136 \\
\hline
\end{tabular}

Fonte: Matriz de Informações Sociais - Setembro 2010. CGEP/DESAN/SESAN/MDS 


\section{Anexo B - Tipologia das Cozinhas Comunitárias da REDESAN}

\begin{tabular}{|c|l|}
\hline Tipo 1 & $\begin{array}{l}\text { Cozinhas em instituições sociais - apoiadas no início do Programa } \\
\text { Cozinhas Comunitárias em 2003 e 2004. Fazem parte deste grupo os } \\
\text { convênios 133/2004, com o estado do Paraná com unidades } \\
\text { implantadas em áreas de assentamentos a acampamentos da } \\
\text { Reforma Agrária e Associações Comunitárias. }\end{array}$ \\
\hline Tipo 2 & $\begin{array}{l}\text { Cozinhas em creches e escolas de ensino básico e fundamental - } \\
\text { apoiadas no início do Programa Cozinhas Comunitárias, em 2004, } \\
\text { grande parte desse grupo foi do convênio 159/2004 com o Governo do } \\
\text { estado de Santa Catarina com unidades instaladas em Escolas } \\
\text { Estaduais de ensino fundamental. }\end{array}$ \\
\hline Tipo 3 & $\begin{array}{l}\text { Cozinhas Profissionalizantes com geração de emprego e renda - não } \\
\text { servem refeições, realizam cursos na área de inclusão produtiva, } \\
\text { social e educação alimentar. }\end{array}$ \\
\hline Tipo 4 & $\begin{array}{l}\text { Cozinhas descentralizadas - as refeições não são realizadas na } \\
\text { unidade, o usuário recebe marmitex. }\end{array}$ \\
\hline Tipo 5 & $\begin{array}{l}\text { Cozinhas como Equipamentos Públicos de Alimentação e Nutrição } \\
\text { (EPAN) - caracterizados pela produção e comercialização de } \\
\text { alimentos saudáveis a preços acessíveis à população em situação de } \\
\text { vulnerabilidade alimentar, devendo servir um mínimo de 100 refeições } \\
\text { diárias, ao menos 5 dias por semana. É a diretriz apoiada atualmente } \\
\text { pelo MDS. }\end{array}$ \\
\hline
\end{tabular}

Fonte: CGEP/DESAN/SESAN/MDS - adaptado 